\title{
Structure and dynamics of the Indian-Ocean cross-equatorial cell
}

\author{
Toru Miyama ${ }^{\mathrm{a}, *}$, Julian P. McCreary Jr. a , Tommy G. Jensen ${ }^{\mathrm{a}}$, \\ Johannes Loschnigg ${ }^{\mathrm{a}}$, Stuart Godfrey ${ }^{\mathrm{b}}$, Akio Ishida ${ }^{\mathrm{c}}$ \\ ${ }^{a}$ International Pacific Research Center, University of Hawaii, Honolulu, HI, USA \\ ${ }^{\mathrm{b}}$ CSIRO, Hobart, Tasmania, Australia \\ c Japan Marine Science and Technology Center, Yokosuka, Japan
}

\begin{abstract}
The cross-equatorial cell (CEC) in the Indian Ocean is a shallow $(z \gtrsim-500 \mathrm{~m})$ meridional overturning circulation, consisting of northward flow of southern-hemisphere thermocline water, upwelling in the northern hemisphere, and a return flow of surface water. In this study, several types of ocean models, varying in complexity from a $1 \frac{1}{2}$-layer analytic model to a state-of-the-art general circulation model (GCM), are used to investigate CEC structure and its dynamics.

Pathways are illustrated by tracking model drifters from the northern-hemisphere upwelling regions, both forwards in time to follow the surface pathways and backwards in time to follow the subsurface flows. In the subsurface branch, cross-equatorial flow occurs via a western-boundary current, where strong horizontal mixing can alter the sign of its potential vorticity. In contrast, surface pathways cross the equator in the interior ocean at almost all longitudes. Sources of CEC water are flow into the basin in the southeastern ocean, subtropical subduction, and the Indonesian Throughflow. The models differ in which source is most prominent, a consequence of their different parameterizations of vertical-mixing processes and basin boundary conditions.

The surface, cross-equatorial branch is driven by the annual-mean component of the zonal wind stress $\tau^{x}$. It is predominantly antisymmetric about the equator with westerlies (easterlies) north (south) of the equator, and so is roughly proportional to latitude $y$. The resulting negative wind curl drives a southward Sverdrup flow across the equator. For a $\tau^{x}$ that is exactly proportional to $y$, the Ekman pumping velocity is identically zero; as a consequence, no geostrophic currents are generated by the wind, and the Sverdrup transport is equal to the Ekman drift.

In GCM solutions, the southward, cross-equatorial flow occurs just below the surface $(z<-100 \mathrm{~m})$, typically beneath a northward surface current, so that there is a shallow, cross-equatorial "roll". This feature is the direct (local) response to southerly cross-equatorial winds, and its basic dynamics are linear. Because it is so shallow, the roll has little impact on the CEC heat transport. It does, however, influence where surface drifters can cross the equator; they cross near the eastern boundary where the roll is weak.
\end{abstract}

(C) 2003 Elsevier Science Ltd. All rights reserved.

\footnotetext{
*Corresponding author. Frontier Research System for Global Change, 3173-25 Showamachi Kanazawa-ku, Yokohama City, Kanagawa 236-0001, Japan. Tel.: +81-45-778-5682; fax: +81-45-778-5707.

E-mail address: tmiyama@jamstec.go.jp (T. Miyama).
} 


\section{Introduction}

\subsection{Observational background}

Tropical circulations in the Indian Ocean differ considerably from those in the Atlantic and Pacific Oceans because the driving wind field is so different. In marked contrast to other oceans, the near-equatorial zonal winds tend to be antisymmetric about the equator, circulating clockwise during the southwest monsoon and counterclockwise during the northeast monsoon (Fig. 1). The equatorial winds are weak throughout the year, and are strongest during the inter-monsoons (April and October) when they are westerlies. The southwest monsoon winds dominate the annual cycle, so that the annual-mean wind field has a structure much like that in July.
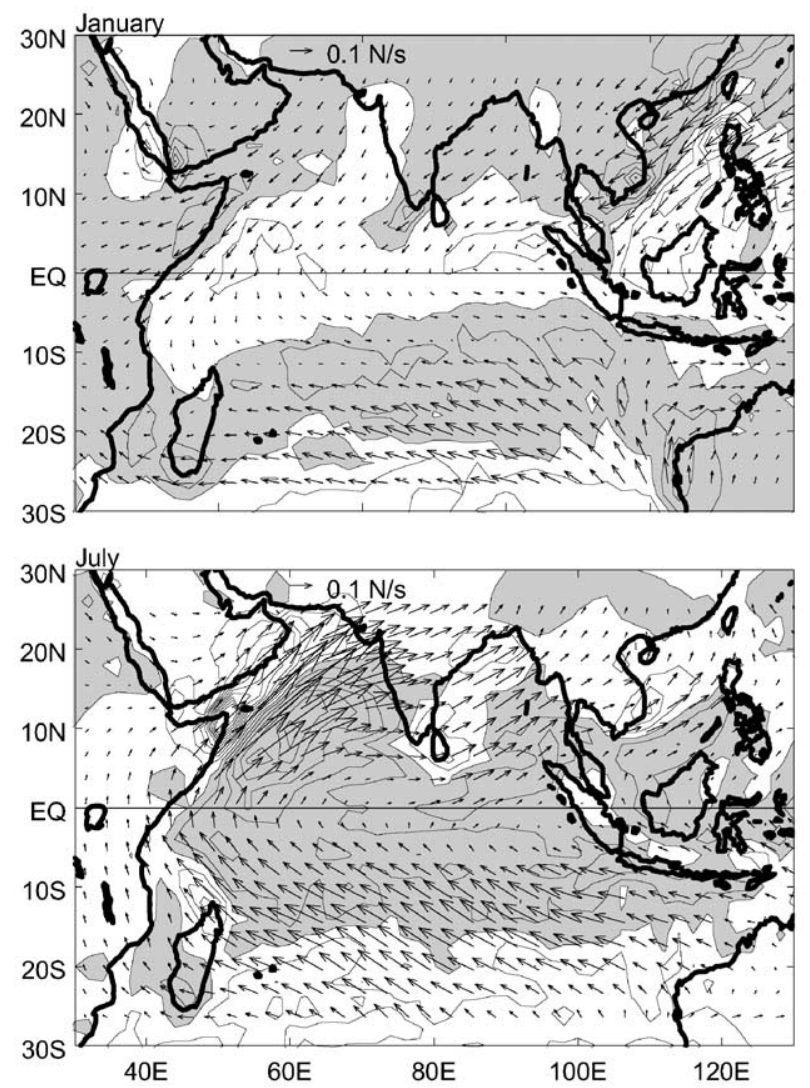

Because of this forcing, significant upwelling typically does not occur along the equator in the Indian Ocean, but rather in the northern hemisphere off Somalia, Oman and India. The upwelled water can come from depths of 200$300 \mathrm{~m}$, occasionally with temperatures colder than $15^{\circ} \mathrm{C}$ and densities in excess of $\sigma_{\theta}=26.5 \mathrm{~kg} / \mathrm{m}^{3}$ (Schott and McCreary, 2001). These temperatures and densities correspond to those in southern midlatitudes near $40^{\circ} \mathrm{S}$, and the relatively low salinities of the water upwelled off Somalia also clearly identify it as being of southern-hemisphere origin (Fischer et al., 1996). Hence, the zonally integrated meridional circulation has a shallow overturning cell, with a northward subsurface branch supplying the northern-hemisphere upwelling and a southward surface branch returning it to the southern Indian Ocean. Moreover, there is a
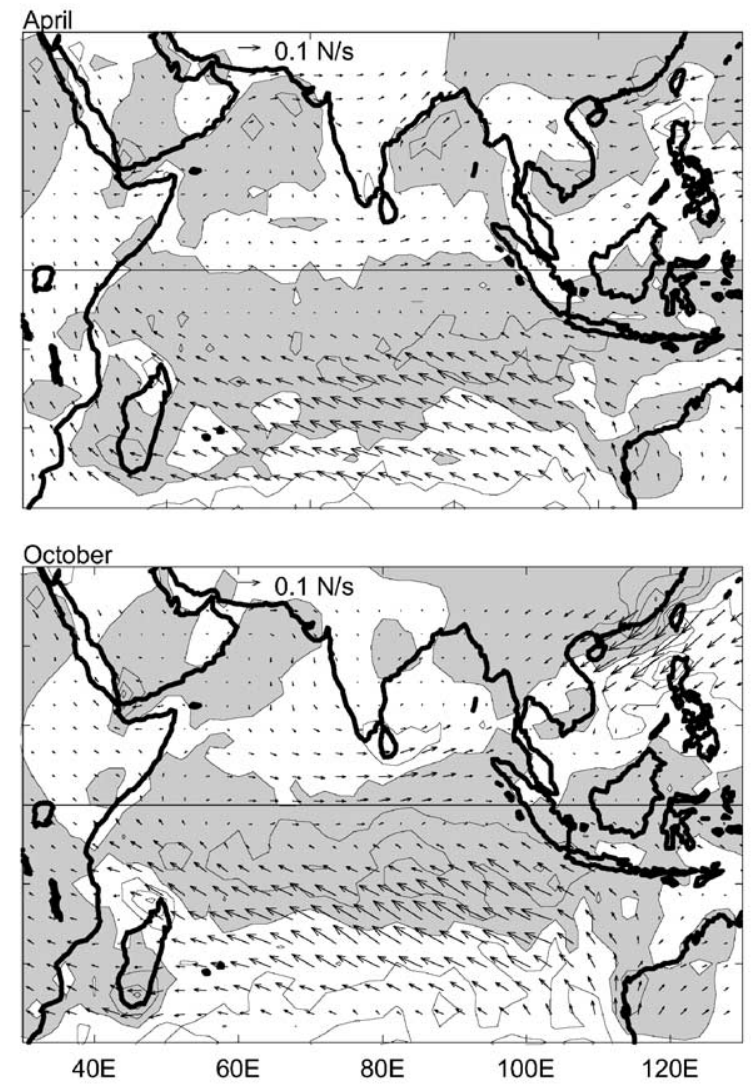

Fig. 1. Wind-stress (arrows) and wind-curl (contours) fields for the Indian Ocean. The contour interval for wind curl is $10^{-7} \mathrm{~N} / \mathrm{m}^{3}$, and negative values are shaded. After Hellerman and Rosenstein (1983). 
net southward heat transport associated with this flow since the subsurface branch imports cool water into the northern hemisphere and the surface branch exports warm water. We refer to this circulation as the cross-equatorial cell (CEC).

Two other shallow overturning cells are defined by upwelling regions in the southern hemisphere. One is closed by upwelling in a band from $5^{\circ} \mathrm{S}$ to $10^{\circ} \mathrm{S}$ in the central and western ocean, the subtropical cell (STC). It is driven by the negative wind curl in the region associated with the equatorward weakening of the Southeast Trades (Fig. 1). There is clear observational evidence that isopycnals rise close to the surface in the region, but little indication of actual upwelling in seasurface temperature (SST) (Spencer et al., 1982; Wyrtki, 1988; Levitus and Boyer, 1994; Levitus et al., 1994). On the other hand, there is support for this upwelling in satellite measurements of ocean color, which sometimes indicate the presence of phytoplankton blooms in this band (Murtugudde et al., 1999). See McCreary et al. (1993; hereafter MKM), Schott and McCreary (2001), and Schott et al. (2002) for a further discussion of this cell. The other cell is associated with upwelling in the eastern, equatorial ocean, along the Java and Sumatran coasts, in the Arafura Sea, and occasionally along the equator; it can be viewed as an eastern branch of the STC, which we refer to as the "eastern STC". All three cells are analogous to the STCs in the Pacific and Atlantic Oceans, except that the latter are closed almost entirely by equatorial upwelling ( $\mathrm{Lu}$ et al., 1998; Huang and Liu, 1999; Rothstein et al., 1998; Malonotte-Rizzoli et al., 2000).

Observational evidence for the three-dimensional structure and strength of the CEC is discussed in Schott et al. (2002). Southern-hemisphere thermocline water moves westward in the South Equatorial Current (SEC) and then northward in the East African Coastal Current (EACC). Part of this subsurface flow bends eastward just south of the equator to join the South Equatorial Countercurrent, and about $10 \mathrm{~Sv}$ cross the equator as part of the Somali Current. The cross-equatorial flow eventually upwells in the northern hemisphere to participate in the CEC. The upwelled water advects slowly eastwards and southwards across the Arabian Sea, and eventually crosses the equator. Surface drifters indicate that much of this cross-equatorial surface flow takes place near the eastern boundary, but this result may be a distortion caused by the presence of "equatorial rolls" (see Fig. 2 and Section 5).

Levitus (1987), Jayne and Marotzke (2001), and others have hypothesized that the cross-equatorial surface transport results from the Ekman drift being directed southward on both sides of the equator during the summer monsoon and in the annual mean, a consequence of the zonal winds being westerly north of the equator and easterly south of the equator (bottom-left panel of Fig. 1). In itself, however, this hypothesis is unsatisfying because it neglects the possible role of geostrophic currents and simply because Ekman theory breaks down at the equator where the Coriolis parameter vanishes.

\subsection{Modeling background}

The CEC is present in solutions to several oceanic general circulation models (GCMs), as revealed in plots of zonally averaged, meridional streamfunctions (Wacongne and Pacanowski, 1996; Garternicht and Schott, 1997; Lee and Marotzke, 1997, 1998). Fig. 2 shows the annualmean streamfunction in the upper $500 \mathrm{~m}$ from the Japan Marine Science and Technology Center (JAMSTEC) GCM, which has a structure similar to those in the other solutions. Associated with the CEC, there is northward subsurface flow and a compensating southward flow within the upper $50 \mathrm{~m}$, with a strength of $6 \mathrm{~Sv}$. There is also a very shallow recirculation cell centered on the equator, an "equatorial roll". As a result, the southward branch of the CEC occurs underneath a northward surface current. This roll was first noted by Wacongne and Pacanowski (1996), who hypothesized that it was a response to southerly, crossequatorial winds, as in the idealized solutions forced by uniform southerly winds reported by Philander and Delecluse (1983; also see McCreary, 1985). Note that there also appears to be upwelling from about $5^{\circ} \mathrm{S}$ to the left edge of Fig. $2\left(8^{\circ} \mathrm{S}\right)$ with a strength of about $5 \mathrm{~Sv}$, the upwelling branch of the model's STC. (Fig. 2 cuts off at $8^{\circ} \mathrm{S}$ because 


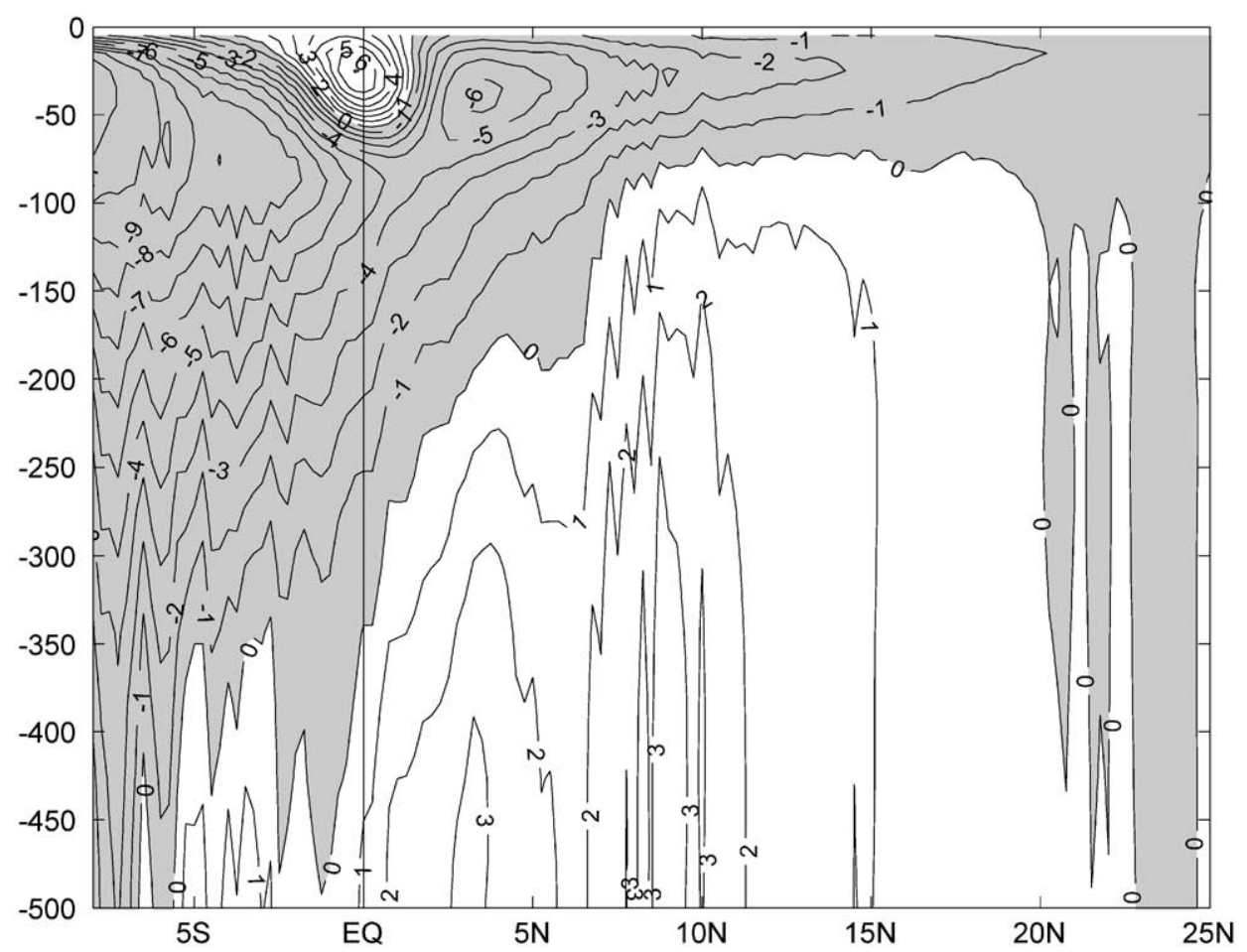

Fig. 2. Meridional streamfunction in the northern Indian Ocean calculated from the annual-mean velocity field of the JAMSTEC solution.

the Indonesian Throughflow, which begins at that latitude, prohibits the definition of a streamfunction.)

So far, three-dimensional CEC pathways have not been discussed in detail for GCM solutions, but they have for solutions to layer models. MKM described the annual-mean pathways of the CEC in their solution to a $2 \frac{1}{2}$-layer model, finding good agreement with the observed properties noted above (see Figs. 3 and 6). They also discussed two-dimensional aspects of the CEC, among other things describing its role in the zonally integrated heat balance. Haines et al. (1999) diagnosed the subsurface CEC pathways in solutions to their $3 \frac{1}{2}-$ layer model by tracking Lagrangian tracers within layer 2 (the thermocline layer). Their analyses showed that layer-2 water flowed into the northern Arabian Sea via the western boundary current, and that its primary sources were flow into the basin across southern and eastern open boundaries.

\subsection{Present research}

In this paper, we utilize a suite of ocean models, varying in complexity from an analytic $1 \frac{1}{2}$-layer system to a state-of-the-art GCM, to investigate CEC structure and dynamics. Specific goals are to describe its complete three-dimensional flow field (Section 3), determine the processes that drive its cross-equatorial flow (Section 4), and understand the dynamics and consequences of equatorial rolls (Section 5).

Results include the following. Source waters for the CEC are subtropical subduction, flow into the basin across the southern boundary, and the Indonesian Throughflow. The annual-mean, surface, cross-equatorial flow is a southward Sverdrup flow driven by negative curl of the annual-mean winds, which circulate clockwise about the equator (as in the bottom-left panel of Fig. 1). Equatorial rolls are a secondary aspect of the CEC, having little effect on the heat transport 

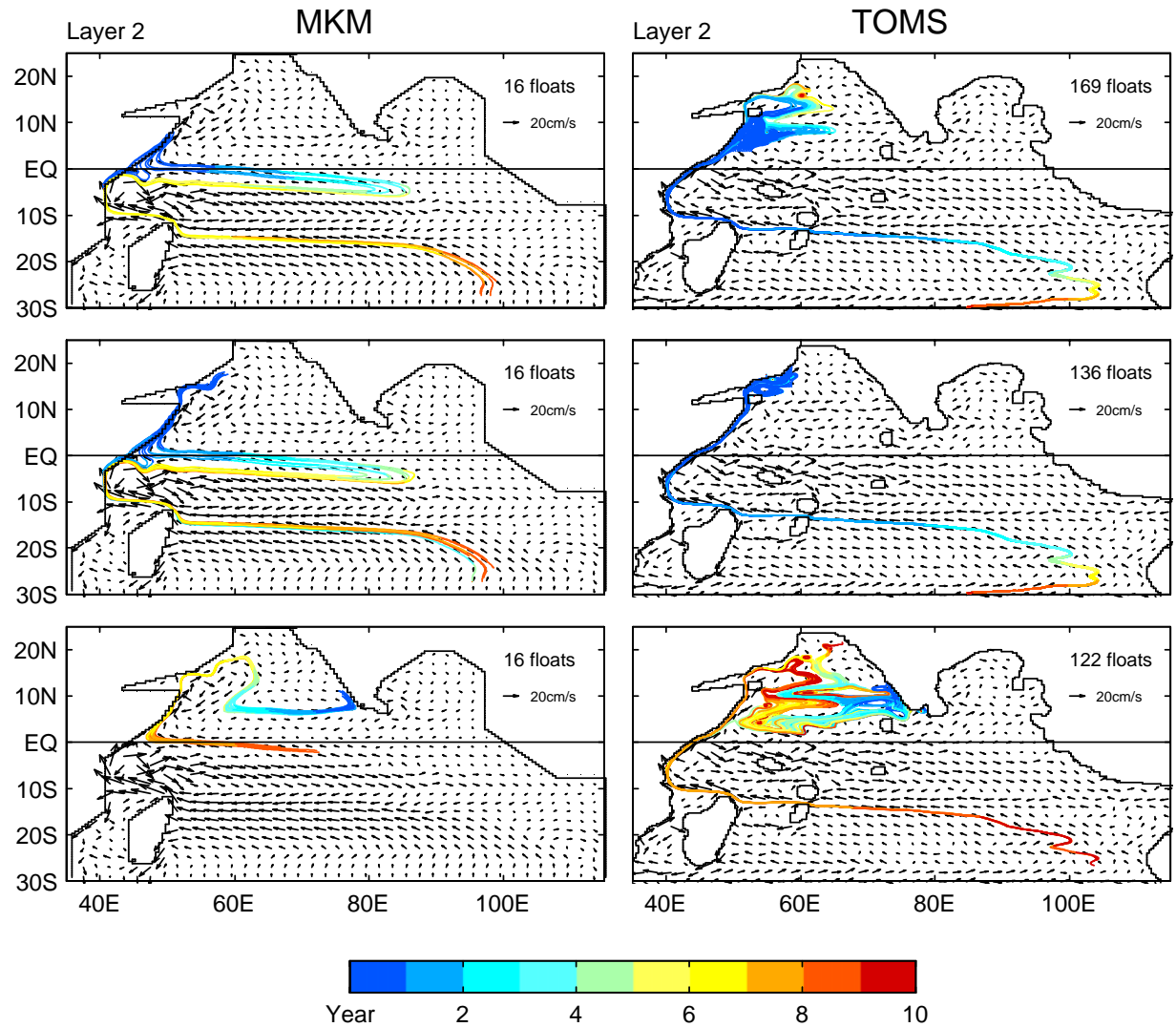

Fig. 3. Drifter trajectories tracked backwards in time using annual-mean, layer-2 flow fields from the MKM (left panels) and TOMS (right panels) solutions. Drifters are released near Somalia (top), Oman (middle) and India (bottom). Color indicates the time in years since the release of the drifter.

because they are equatorially and surface trapped. They do, however, alter the surface flow field in GCM solutions, forcing it to cross the equator near the eastern boundary, consistent with the drifter observations.

\section{The ocean models}

The five models utilized in this study are: (i) an analytic, $1 \frac{1}{2}$-layer model; (ii) two variable-density layer models; (iii) a linear, continuously stratified (LCS) model; and (iv) a state-of-the-art GCM. Each model has its own usefulness. The analytic model isolates the physics of the surface equatorial flow. Because of their simplified vertical structure, the layer models illustrate CEC structure more easily, its surface and subsurface branches being confined to layers 1 and 2, respectively. The GCM has the most complete physics, and hence can simulate the circulations most realistically. Finally, the LCS model reproduces the structure of the near-equatorial flow field of the GCM remarkably well, and so provides a valuable analysis tool. All the models are forced by Hellerman and Rosenstein (1983) wind stress (Fig. 1). Results were not significantly changed in a test solution to one of the layer models (TOMS, described below) forced by ECMWF winds.

The analytic model is a $1 \frac{1}{2}$-layer system. Its equations of motion are:

$$
\begin{aligned}
& -f h v+\frac{1}{2} g^{\prime}\left(h^{2}\right)_{x}=\tau^{x}, \\
& f h u+\frac{1}{2} g^{\prime}\left(h^{2}\right)_{y}=0, \\
& h_{t}+(h u)_{x}+(h v)_{y}=0,
\end{aligned}
$$


where $u$ and $v$ are the zonal and meridional velocities, respectively, $h$ is the thickness of the active layer, $f$ is the Coriolis parameter, and $g^{\prime}$ is the reduced-gravity coefficient. For convenience, we neglect the acceleration terms, $u_{t}$ and $v_{t}$. The neglect of $v_{t}$, referred to as the "long-wavelength approximation", is common in equatorial theory (McCreary, 1985). It eliminates inertial oscillations from the system, and is valid provided that the wind forcing is large scale (larger than the equatorial Rossby radius of deformation) and slowly varying (long with respect to the equatorial inertial period). The neglect of $u_{t}$ is generally not valid near the equator, since, among other things, it adjusts the propagation speed of equatorially trapped, baroclinic waves to $\infty$. The approximation is alright for the specific wind forcing of interest here (a zonal wind stress proportional to $y$ ), because such a wind generates no baroclinic waves and because $u \equiv 0$ (see Section 4.1).

The MKM model consists of two active layers overlying a deep, inert layer, and layer temperatures (densities) are allowed to vary (a variabledensity, $2 \frac{1}{2}$-layer model). It allows water to transfer between layers, and heat and momentum are conserved during such transfers. A bulk mixed layer is imbedded within layer 1, in which entrainment and detrainment are determined from wind stirring and the surface buoyancy flux as in the Kraus and Turner (1967) formulation; however, no shear is allowed between the mixed layer and the rest of layer 1 just below it. Water can freely enter and leave the basin across the open southern boundary, but the eastern boundary is closed so that there is no Indonesian Throughflow. The horizontal resolution of the model is $0.5^{\circ}$, and hence it is not eddy resolving. Solutions are shown after an initial spin-up of 10 years.

The thermodynamic ocean modeling system (TOMS) is similar to the MKM model, except that it allows for salinity variability within layers. It also has the flexibility to include more layers easily, and in the present case it is configured as a $4 \frac{1}{2}$-layer model. It has a bulk mixed layer based on Kraus and Turner (1967) physics, but entrainment is also determined by velocity shear at its base. The entire southern boundary and a segment of the eastern boundary south of Indonesia are open. To maintain the Indonesian Throughflow, the model is nudged towards a constant inflow of $10 \mathrm{~Sv}$ across the open segment. Similarly, to maintain a strong Agulhas Current, it is nudged toward a constant outflow of $30 \mathrm{~Sv}$ across the southern boundary between the coast of Africa and $39^{\circ} \mathrm{E}$. Transports along the two nudging segments are distributed evenly among the four layers using a flow relaxation scheme (Jensen, 1998). The layer-1 temperature and salinity fields are relaxed to SST and SSS fields from the World Ocean Atlas 1994 monthly climatology (Levitus et al., 1994; Levitus and Boyer, 1994) with an e-folding time of 6 days. The model's resolutions is $0.33^{\circ}$, so that it is eddy permitting. Results from years 3 to 6 of the integration are shown below.

The JAMSTEC GCM is a high-resolution global GCM with a horizontal resolution of $0.25^{\circ}$ and 55 vertical levels (Ishida et al., 1998). It is based on version 2 of the Modular Ocean Model (MOM2; Pacanowski, 1995). Coefficients of vertical mixing are specified according to the sheardependent Pacanowski and Philander (1981) scheme. Heat and freshwater fluxes are implemented as a linear restoring of temperature and salinity toward Levitus (1982) SST and SSS data in the first model level with a time scale of 6 days. Results from year 20 of the integration are shown.

The LCS model is described in detail in McCreary et al. (1996; also see McCreary, 1985). It is a linearization of the primitive equations about a background state of rest with BruntVäisälä frequency $N_{\mathrm{b}}(z)$, which is determined from the annual-mean density field from the JAMSTEC solution averaged from $5^{\circ} \mathrm{S}$ to $5^{\circ} \mathrm{N}$ and $40^{\circ} \mathrm{E}$ to $100^{\circ} \mathrm{E}$. There is vertical mixing with a coefficient of the form $v=A / N_{\mathrm{b}}^{2}$, and unless specified otherwise $A=52 \times 10^{-4} \mathrm{~cm}^{2} / \mathrm{s}^{3}$. With this choice, $v$ varies from $0.2 \mathrm{~cm}^{2} / \mathrm{s}$ (where $N_{\mathrm{b}}^{2}$ is a maximum) to $10 \mathrm{~cm}^{2} / \mathrm{s}$ in the upper $100 \mathrm{~m}$ of the water column. A simple mixed layer is also included by introducing wind stress into the system as a body force with the vertical structure

$$
Z(z)=\frac{2}{\left|z_{1}+z_{2}\right|}\left\{\begin{array}{cc}
1, & z>z_{1} \\
\frac{z-z_{2}}{z_{1}-z_{2}}, & z_{1} \geqslant z>z_{2}, \\
0 & z_{2} \geqslant z,
\end{array}\right.
$$


where $z_{1}=-10 \mathrm{~m}$ and $z_{2}=z_{1}-10 \mathrm{~m}$. It is also possible to obtain solutions with $z_{1}=z_{2}=0$, in which case the forcing enters the ocean as a surface stress condition.

The ocean bottom of the LCS model is assumed flat at a depth of $D=4000 \mathrm{~m}$. With this restriction and the particular form of $v$ noted above, solutions can be represented as expansions in the vertical normal modes of the system. To calculate solutions, the response of each mode is obtained numerically on a staggered grid with a horizontal resolution of $0.25^{\circ}$, and the contributions from each mode summed. The number of modes used is $N=50$, for which solutions are well converged. Integrations are started from a state of rest, spun up for a period of 10 years, and the solutions shown are all taken from the final year of the integration.

\section{CEC structure}

In this section, we first describe the threedimensional pathways of the CECs in the MKM, TOMS, and JAMSTEC solutions by tracking model drifters. We conclude by reporting the transports associated with the CEC's prominent branches. As we shall see, the overall pathway structure is similar among the three solutions, as it is largely determined by the ocean's adjustment to the basin-scale wind field. Particular pathway segments, however, are model sensitive, as their dynamics depend on second-order physics (rectification of annual and higher-frequency variability, mixed-layer parameterizations, entrainment/detrainment processes, etc.) and basin boundary conditions. We provide plausible explanations for prominent differences among the solutions, but a detailed examination of their causes is beyond the scope of this study.

\subsection{Methodology}

The drifters are added in (or near) the three prominent upwelling regions in the northern ocean (near Somalia, Oman, and the southern tip of India), since they are the "windows" where the subsurface branch of the CEC ascends to the surface. To identify the surface CEC pathways, we track drifters forward in time from the upwelling regions. Conversely, to locate the subsurface ones, we track them backwards in time.

For the JAMSTEC solution, drifters are usually advected by the complete velocity field, that is, including the vertical-velocity component, the exception being for the particle trajectories shown in Fig. 13. For the MKM and TOMS solutions, only the layer-1 and layer-2 flow fields are used, so that any transfer of drifters between layers by entrainment and detrainment is ignored.

Both annual-mean (Section 3.2) and instantaneous (Section 3.3) currents are used to determine drifter trajectories, and we refer to the two trajectory types as "annual-mean" and "instantaneous" pathways, respectively. Given the large annual variation of the Indian-Ocean monsoon currents, the instantaneous pathways are quite complex, among other things depending on their release time. Nevertheless, the annual-mean trajectories capture basic features of the instantaneous ones, illustrating them more clearly.

\subsection{Annual-mean trajectories}

\subsubsection{Subsurface branch}

Figs. 3 and 4 show subsurface CEC pathways for the MKM, TOMS, and JAMSTEC solutions. For the two-layer model solutions (Fig. 3), trajectories tend to follow similar pathways regardless of the initial location of drifters. In contrast to the layer-model solutions, trajectories in the JAMSTEC solution are highly sensitive to initial location, likely because its annual-mean flow field contains even smaller features than the TOMS solutions does, and because drifters are tracked vertically as well as horizontally. For this reason, Fig. 4 provides four single trajectories that illustrate typical pathways, and, to illustrate track variability, Fig. 5 plots trajectory end points.

North of the equator, pathways in the MKM solution extend directly southward along the Somali coast to cross the equator, whereas many of the TOMS trajectories first recirculate in the Arabian Sea. A likely cause of this model difference is that TOMS is eddy permitting, and hence even its annual-mean flow field contains 

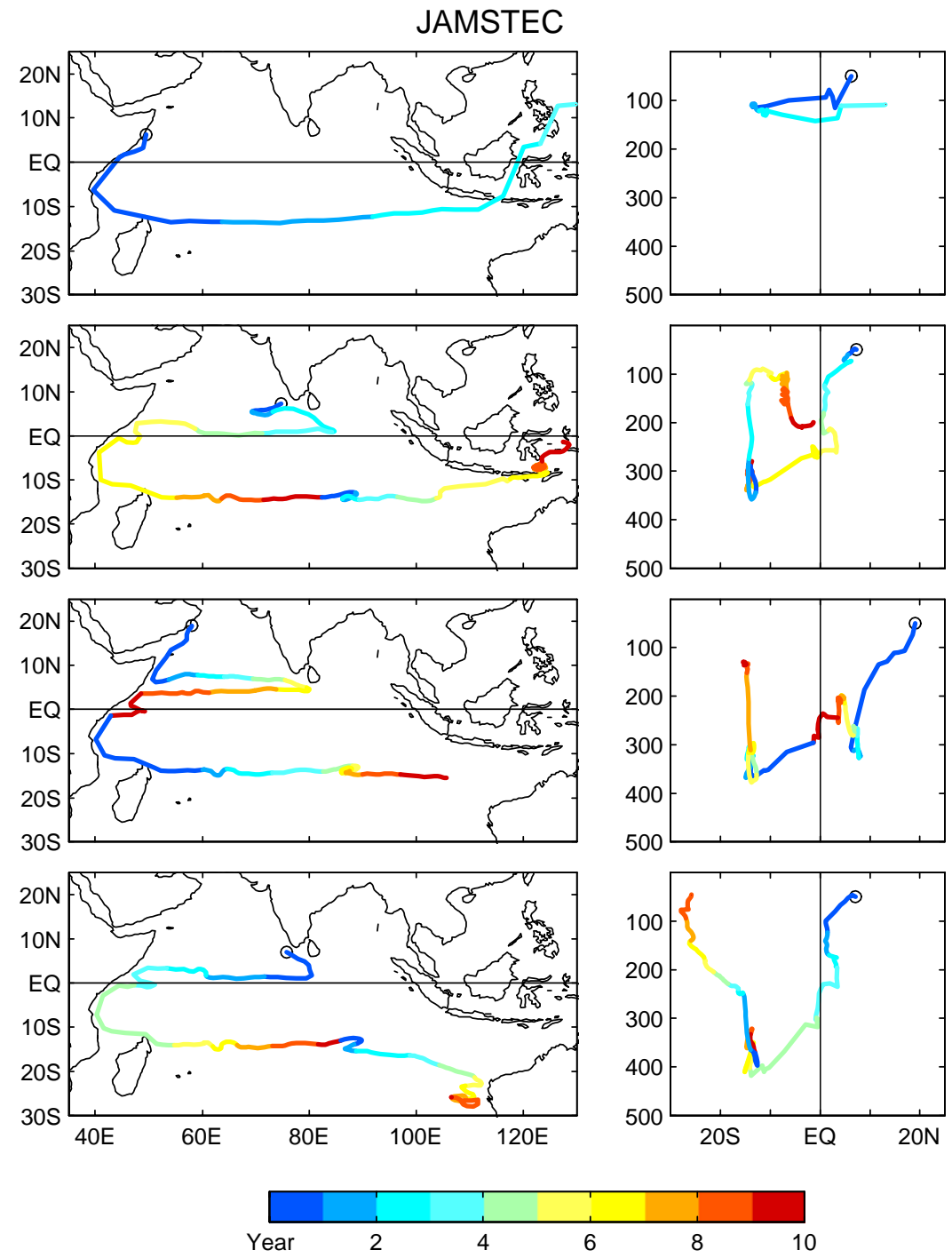

Fig. 4. Four drifter trajectories tracked backwards in time using the annual-mean velocity field of the JAMSTEC solution, showing $x-y$ and $y-z$ views in corresponding left and right panels. The trajectories illustrate types of commonly occurring pathways. Color indicates the time in years since the release of the drifter and colors repeat after 10 years.

small-scale features. Another possibility is that the TOMS solution has narrower currents because of its higher resolution, so that it is easier for some drifters to enter recirculating regimes; in support of this idea, some MKM drifters also recirculate in the Arabian Sea when their starting location is somewhat broadened. South of the equator, drifter trajectories are tightly packed in both solutions, but particularly for the TOMS trajectories, which virtually overlie each other. Since the subsurface drifters are advected backwards in time, their convergence onto a single trajectory indicates the presence of a divergent layer-2 velocity field, a result of the subduction that occurs in the region.

For the layer models, the upwelling areas off Somalia, Oman, and India are sequentially linked: Pathways that end off India must first pass Somalia and Oman; likewise, pathways that end 


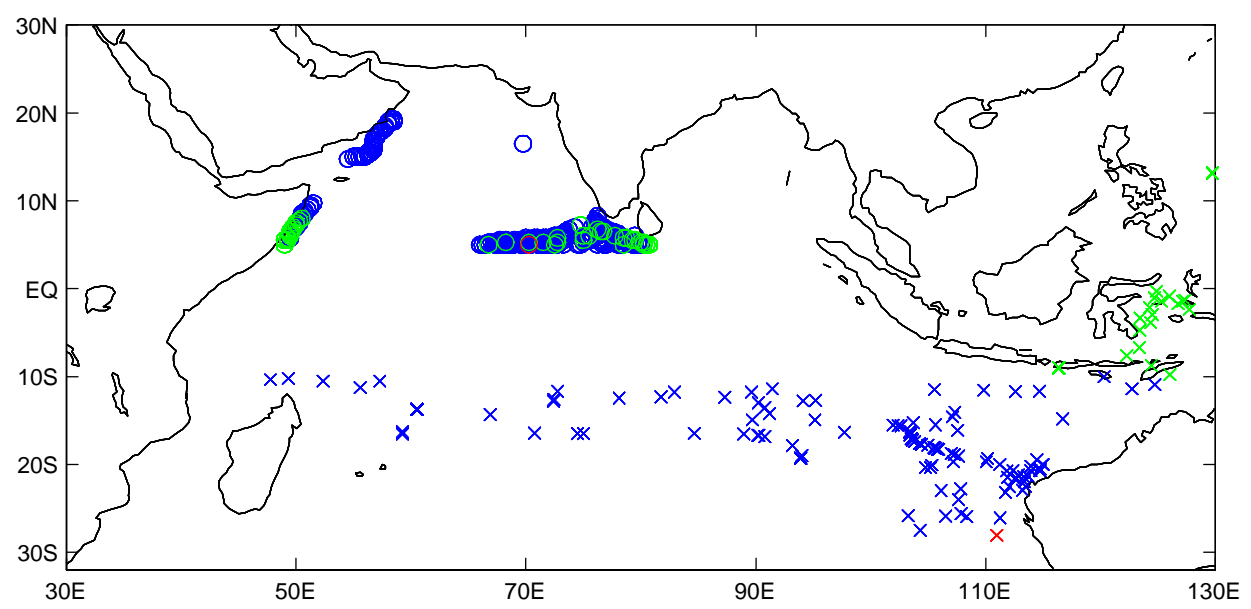

Fig. 5. Initial (crosses) and final (circles) points of trajectories tracked backwards in time using the annual-mean flow field of the JAMSTEC solution, showing trajectories that end in the subduction region (blue), the Indonesian seas (green), and at $30^{\circ} \mathrm{S}$ (red).

off Oman must first pass Somalia (middle and bottom panels of Fig. 3). In contrast, no trajectories extend directly from Somalia to Oman in the JAMSTEC solution. Interestingly, Oman and India are connected to Somalia by a circuitous route, with subsurface water extending to India in a current just north of the equator and to Oman only after an excursion across the Arabian Sea (middle panels of Fig. 4). Instantaneous trajectories, however, can take a direct pathway, a consequence of increased mixing by eddies.

Pathways from all three models almost always cross the equator along the western boundary. This property is reasonable, since the strong horizontal mixing in the western boundary current is needed in order to reverse the sign of the fluid's potential vorticity. The only exception is for the MKM solution (left panels of Fig. 3), for which some trajectories cross the equator as far east as $60^{\circ} \mathrm{E}$ in association with a zonally elongated recirculation gyre centered just south of the equator. Some instantaneous trajectories also follow this pathway, so it is not an artifact of tracking by the annual-mean flow field. Note that it takes drifters near the equator about 3 years to move from the central ocean to the western boundary. So, instantaneous trajectories that follow this annual-mean recirculation actually go through large excursions along the equator during each year. Water parcels along this trajectory gain the positive potential vorticity they need to cross the equator either through horizontal mixing or rectification of the annual cycle. It is not clear why the MKM solution has this near-equatorial recirculation but the TOMS solution does not. A possible reason is that the western boundary current extends somewhat farther northward in the TOMS solution so that it gains a bit more positive potential vorticity before retroflecting offshore, a consequence of its having a higher resolution and narrower, swifter currents.

Trajectories in all the models extend southward along the African coast to about $10^{\circ} \mathrm{S}$ and then eastward along $15^{\circ} \mathrm{S}$. For the layer models, trajectories reach to the southern boundary near $100^{\circ} \mathrm{E}$, indicating that a significant source of water for the CEC lies outside the basin (Section 3.4). Note that trajectories in the MKM and TOMS solutions differ within a few degrees of the southern boundary, a consequence of the two models having different southern boundary conditions: The MKM model relaxes the zonal velocity field to zero there, whereas TOMS does not. For the JAMSTEC solution, most trajectories extend to the Indonesian passages or to subduction regions in the subtropical Indian Ocean (see Fig. 5). In the latter case, water subducts to depths of about $350-375 \mathrm{~m}$ before it flows northward 
across the equator in the western boundary current, and this type of path takes 20 or more years to reach Somalia (lower three panels of Fig. 4; Fig. 2). In the former, water from the Indonesian passages either crosses the Indian Ocean at depths shallower than $200 \mathrm{~m}$ in only 2-3 years or subducts near $90^{\circ} \mathrm{E}$ and thereafter follows a longer subduction pathway to the Somali coast (top and upper-middle panels of Fig. 4, respectively).

Water density is not constant along trajectories in the JAMSTEC solution. Along the deep pathways (lower three panels of Fig. 4), densities are about $26.4 \sigma_{\theta}$, a value close to the densest water that has been observed to upwell off Somalia (Schott and McCreary, 2001). In contrast, the densities of upwelled waters (at the small circles in
Fig. 4) are 24.1, 23.8, 25.3, and $23.2 \sigma_{\theta}$ from the top to bottom panel, respectively. The large decrease in density from subsurface values is accomplished by diapycnal mixing. One can expect, then, that the depth of the subsurface CEC branch is sensitive to the model's parameterization of diffusion. In support of the JAMSTEC result, the subsurface branch is as deep as $500 \mathrm{~m}$ in other GCM solutions (e.g., Wacongne and Pacanowski, 1996; Garternicht and Schott, 1997; Lee and Marotzke, 1997, 1998).

Fig. 5 shows distributions of trajectory endpoints (circles and crosses) in the JAMSTEC solution, determined as follows. Drifters are deployed at a depth of $50 \mathrm{~m}$ at every model grid point north of $5^{\circ} \mathrm{N}$, and then traced back in time for 20 years. Only drifters that cross the equator

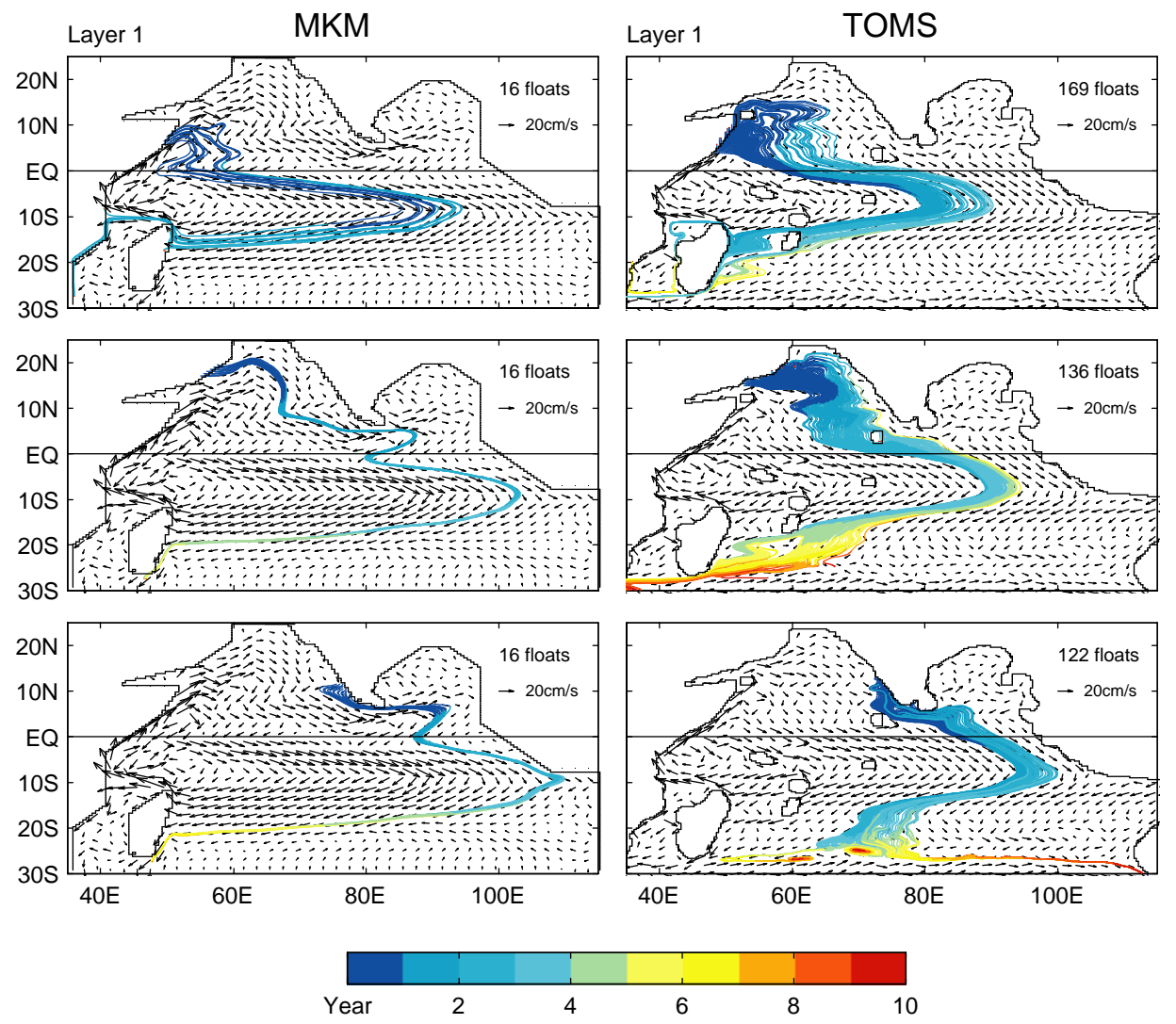

Fig. 6. Drifter trajectories tracked forwards in time using annual-mean, layer-1 flow fields from the MKM (left panels) and TOMS (right panels) solutions. Drifters are released near Somalia (top), Oman (middle) and India (bottom). Color indicates the time in years since the release of the drifter. 
are plotted, and the calculation for that drifter stops if it reaches the surface (blue), $30^{\circ} \mathrm{S}$ (red), or the Indonesian seas (green). Interestingly, the only drifters that ever cross the equator originate in the Somali, Omani, and Indian upwelling regions. Most of the drifters end in the subduction region (blue crosses), a smaller amount end in the Indonesian seas (green crosses), and only one drifter is traced back to $30^{\circ} \mathrm{S}$ (red cross). All the subduction points (blue crosses) originate either north of $18^{\circ} \mathrm{S}$ or east of $100^{\circ} \mathrm{E}$. They lie northeast of the trajectory that extends at a depth of $350 \mathrm{~m}$ (a typical subduction depth in Fig. 4) from the southern boundary to the bifurcation point along Madagascar where the SEC divides to flow north and south along the coast. Water that subducts southwest of this "bifurcation trajectory" exits the basin in the Agulhas Current.

\subsubsection{Surface branch}

Figs. 6 and 7 illustrate surface CEC pathways for the MKM, TOMS, and JAMSTEC solutions. For the two-layer models (Fig. 6), the drifters advect southward and eastward, and cross the equator further to the east for the Somali, Omani, and Indian drifters, respectively. Subsequently, they turn westward near $10^{\circ} \mathrm{S}$ and flow across the basin to the coast of Madagascar. In the MKM solution, they diverge to flow either north or south of the island to the African coast before exiting the basin in the Agulhas Current or south of Madagascar. In contrast, in the TOMS solution, although drifters diverge at the coast, none of them flow through the Mozambique channel to exit the basin. Drifters in the TOMS solution separate more than they do in the MKM solution and bend more to the south poleward of $15^{\circ} \mathrm{S}$; these differences likely result from TOMS having shear between the mixed layer and the layer just beneath it, thereby allowing it to develop stronger surface Ekman flows than the MKM model can. Again, differences near the southern boundary are due to the MKM model damping the zonal velocity to zero there.

For the JAMSTEC solution (Fig. 7), drifters first move to the equator, where they sink to 50 $100 \mathrm{~m}$ due to the equatorial roll seen in Fig. 2.
Some drifters then upwell south of the equator and continue to move southward (upper three panels). Others, however, are entrained into the roll, and undergo 1-2 loops as they are advected eastward (bottom panels). (The MKM and TOMS solutions do not have an equatorial roll since they lack the necessary vertical resolution to represent it.) In the southern Indian Ocean, trajectories can be categorized into four types, in which drifters: (1) subduct in the western half of the subtropics and leave the basin via the Agulhas current (top panel); (2) recirculate in the southern hemisphere at depths shallower than $200 \mathrm{~m}$ (upper-middle panel); (3) move to the eastern boundary and exit the basin via the Leeuwin current (lower-middle panel); and (4) subduct in the eastern half of the subtropics, eventually to recirculate in the CEC (bottom panel).

\subsection{Instantaneous trajectories}

Fig. 8 shows instantaneous backward (left panels) and forward (right panels) trajectories for the TOMS solution for drifters that originate off Somalia (top panels), Oman (middle panels), and the southern tip of India (bottom panels). In each case, drifters are released on June 30 of year 4 , and their positions are updated every $12 \mathrm{~h}$ using velocities updated every 3 days. After year 6 , the 3 years of available model output are repeated to allow the trajectory calculation to be continued for a total of 10 years.

As expected, the instantaneous trajectories are much more varied than their annual-mean counterparts (right panels of Figs. 3 and 6). Nevertheless, the annual-mean trajectories visually emerge in Fig. 8 as preferred pathways. For example, all layer-2 tracks (left panels of Fig. 8) cross the equator in the western boundary current, and extend across the basin from $10^{\circ} \mathrm{S}$ to $20^{\circ} \mathrm{S}$; layer-1 trajectories (right panels of Fig. 8) cross the equator sequentially farther to the east for Somalia, Oman, and India drifters. One prominent difference is that some drifters that originated off Somalia and Oman track back to the open boundary south of Indonesia, whereas none did so in the annual-mean case. Another is that the seasonal cycle enables many floats to be advected 


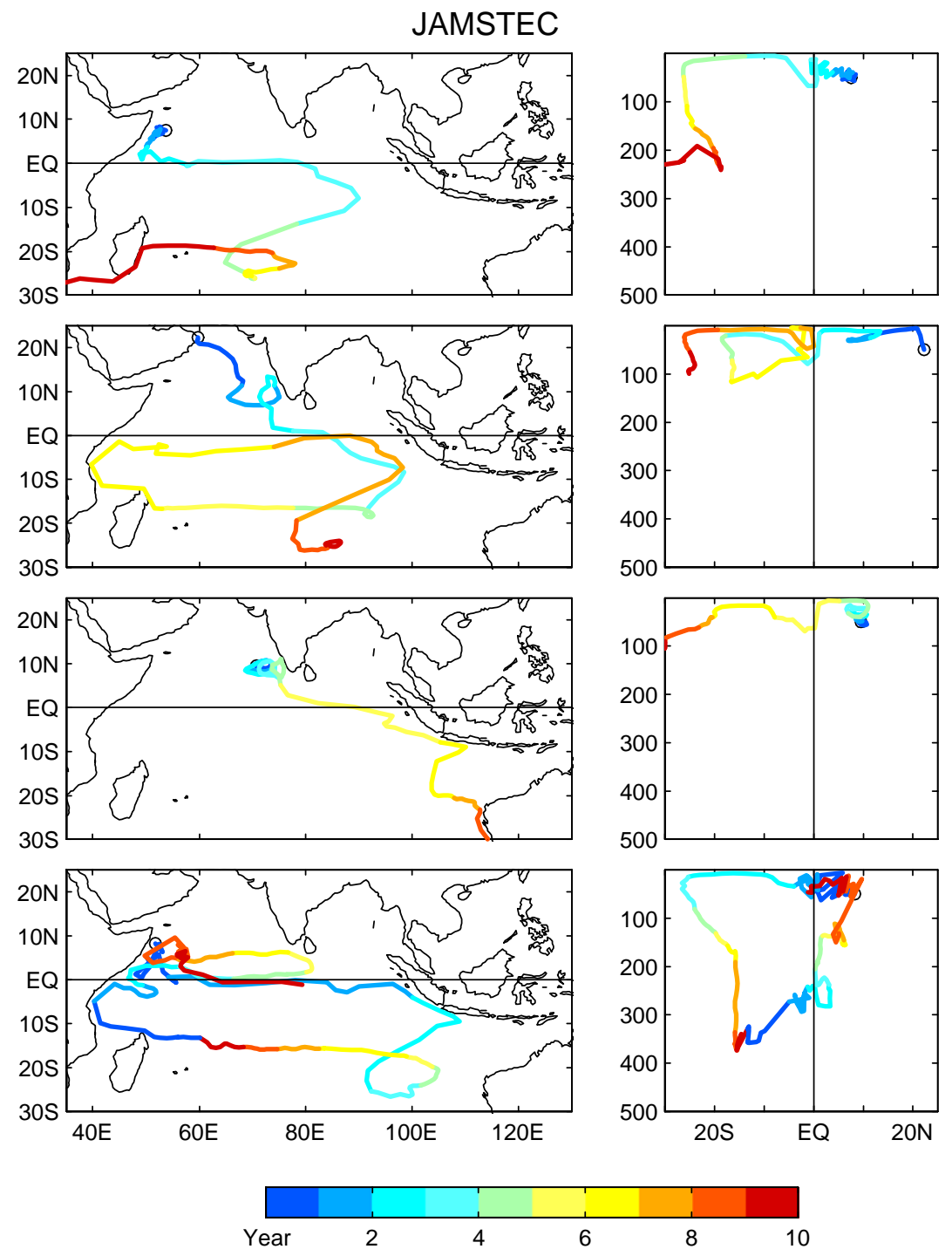

Fig. 7. Four drifter trajectories tracked forwards in time using the annual-mean velocity field of the JAMSTEC solution, showing $x-y$ and $y-z$ views in corresponding left and right panels. The trajectories illustrate types of commonly occurring pathways. Color indicates the time in years since the release of the drifter and colors repeat after 10 years.

northward in the EACC in both layers to reenter the Arabian Sea.

Fig. 9 shows endpoints of instantaneous trajectories for the JAMSTEC solution released on July 1 and tracked backwards in time, which are otherwise determined by the same procedure as in Fig. 5. An obvious difference between the two figures is that the number of drifters that cross the equator is much larger in Fig. 9. Consistent with the Haines et al. (1999) result, this increase happens because more drifters are "mixed" across the equator by higher-frequency variability, and it does not represent an actual strengthening of the CEC. From our analysis, we are unable to tell whether the additional mixing is caused by the annual cycle or by eddies. Haines et al. (1999) also 

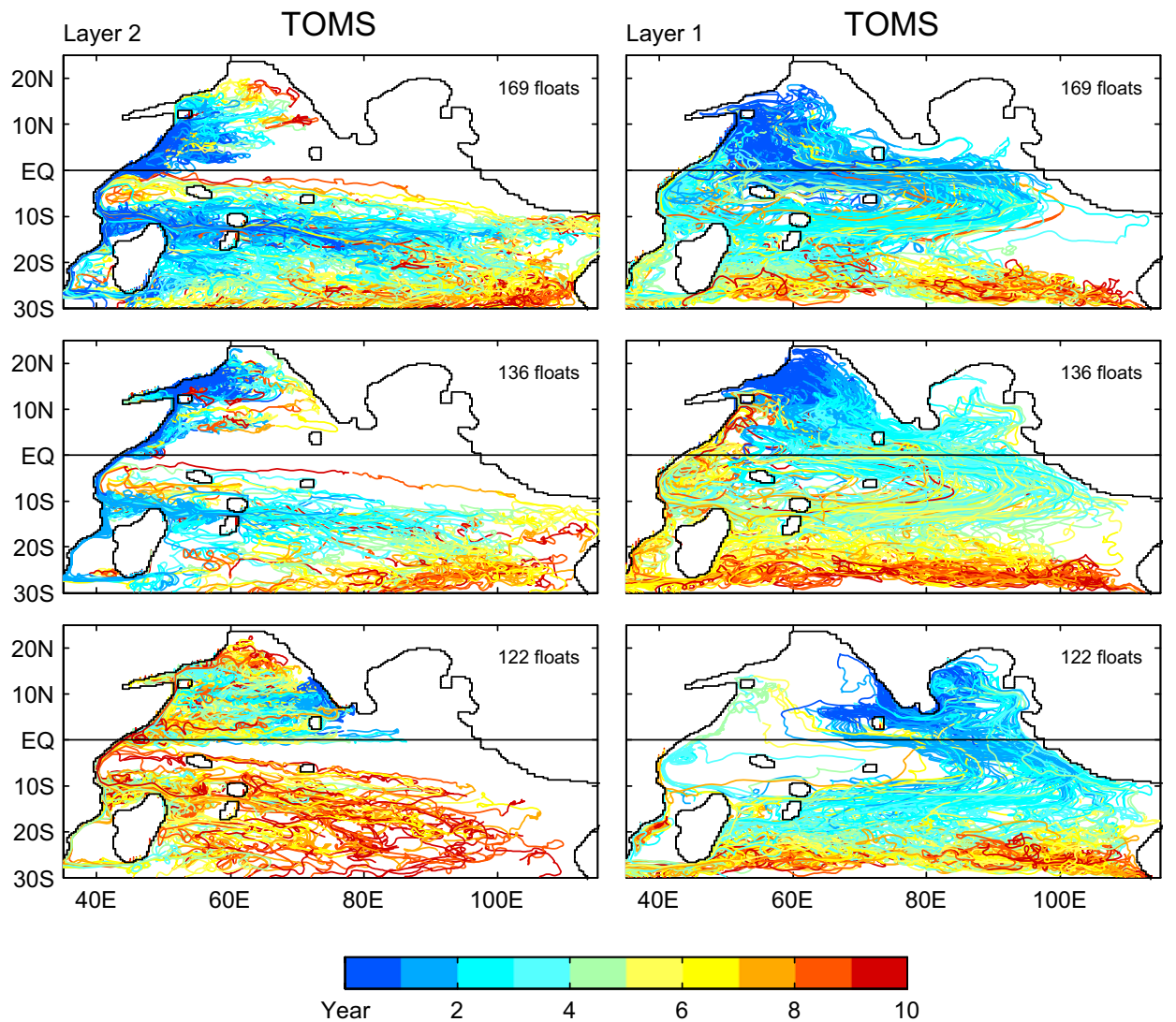

Fig. 8. Drifter trajectories tracked backwards (left panels) and forwards (right panels) in time using instantaneous, layer-2 and layer-1 flow fields, respectively, form the TOMS solution. Drifters are released near Somalia (top), Oman (middle) and India (bottom). Color indicates the time in years since the release of the drifters.

forced their model with annual-mean winds, and concluded from this run that the additional mixing was caused largely by the annual cycle. Another difference is that the relative number of drifters that reach $30^{\circ} \mathrm{S}$ is greatly increased, suggesting that the southern-boundary source of CEC water is underestimated by using annual-mean trajectories. Finally, Indonesian Throughflow water now upwells off Oman, as well as Somalia and India, apparently because of eddy mixing.

\subsection{Transports}

\subsubsection{Upwelling transports}

Table 1 reports strengths of the CEC upwelling branches for the three solutions, listing annual- mean transports of upwelling velocities integrated over areas centered on the upwelling regions off Somalia $\left(x<60^{\circ} \mathrm{E}, \quad 2^{\circ} \mathrm{N}<y<12^{\circ} \mathrm{N}\right)$, Oman $\left(x<60^{\circ} \mathrm{E}, 14^{\circ} \mathrm{N}<y<22^{\circ} \mathrm{N}\right)$, the southern tip of India $\left(72^{\circ} \mathrm{E}<x<85^{\circ} \mathrm{E}, 4^{\circ} \mathrm{N}<y<14^{\circ} \mathrm{N}\right)$, and the entire northern hemisphere $\left(y>0^{\circ}\right.$; NH). For completeness, upwelling transports associated with the STC and the eastern STC are also included, namely, for the upwelling band $\left(50^{\circ} \mathrm{E}<x<90^{\circ} \mathrm{E}\right.$, $12^{\circ} \mathrm{S}<y<2^{\circ} \mathrm{S}$; labeled "Band") and the region near Sumatra $\left(x>100^{\circ} \mathrm{E}, 11^{\circ} \mathrm{S}<y<0^{\circ}\right)$. For the layer models, the upwelling transports are determined using the entrainment velocity $w_{1}$, that is, the rate at which water transfers between layers. For the JAMSTEC model, they are obtained from the vertical-velocity field $w$ at $80 \mathrm{~m}$, and hence 


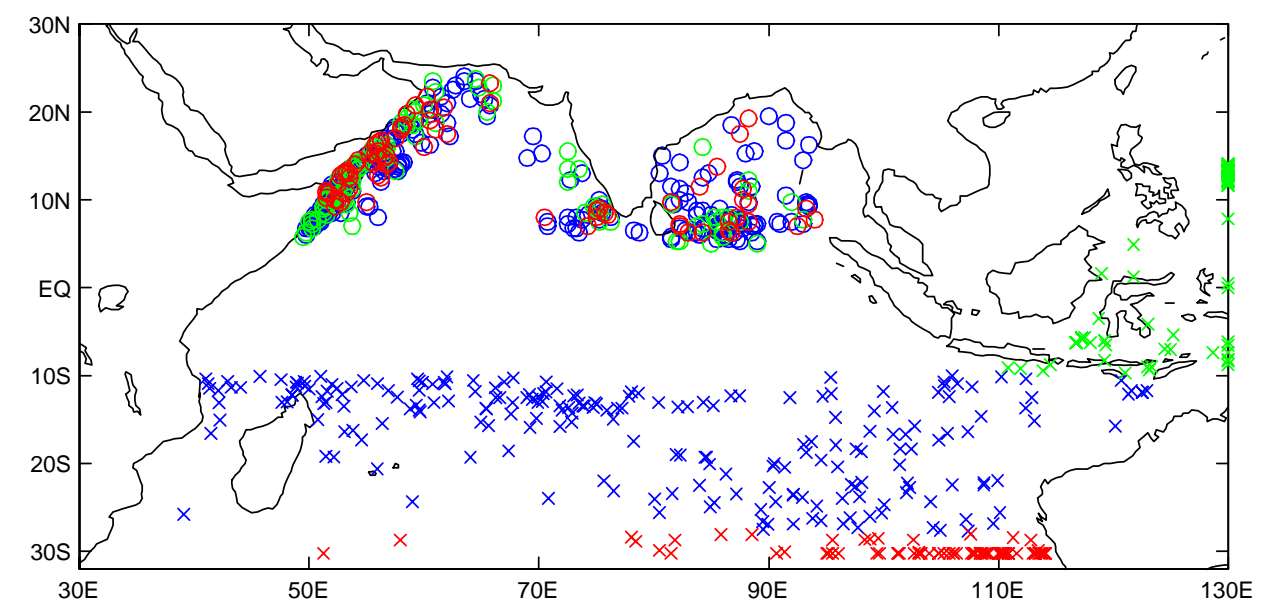

Fig. 9. Initial (crosses) and final (circles) points of trajectories tracked backwards in time using the instantaneous flow field of the JAMSTEC solution, showing trajectories that end in the subduction region (blue), the Indonesian seas (green), and at $30^{\circ} \mathrm{S}$ (red).

Table 1

Annual-mean transports in prominent upwelling regions for the MKM, TOMS, and JAMSTEC solutions

\begin{tabular}{|c|c|c|c|c|c|c|}
\hline \multirow[t]{2}{*}{ Model } & \multicolumn{6}{|l|}{ Region } \\
\hline & Somalia & Oman & India & $\mathrm{NH}$ & Band & Sumatra \\
\hline MKM & $2.7(5.4)$ & $1.9(2.3)$ & $1.8(2.5)$ & $5.8(14.0)$ & $8.0(8.8)$ & $-0.1(0.3)$ \\
\hline TOMS & $1.5(2.9)$ & $1.3(1.8)$ & $1.2(1.5)$ & $5.7(10.6)$ & $4.9(5.7)$ & $2.7(2.9)$ \\
\hline JAMSTEC & $3.1(10.7)$ & $1.0(1.5)$ & $1.2(2.4)$ & $5.2(22.8)$ & $7.5(9.5)$ & $0.6(1.8)$ \\
\hline
\end{tabular}

The transports (Sv) are obtained by integrating either entrainment velocity $w_{1}$ for the MKM and TOMS solutions or vertical velocity $w$ for the JAMSTEC solution over areas centered on the various upwelling regions. Transports without (with) parentheses are determined by integrating net (positive-only) upwelling velocities. The precise locations of the regions are defined in the text.

involve both diapycnal and isopycnal motions. The $80-\mathrm{m}$ depth is chosen to be deep enough to avoid the influence of the equatorial roll (Fig. 2) on the Somali and northern-hemisphere transports, but it does not much affect other transport values.

Both the net and positive-only part (in parentheses) of the transports are listed for each region. The net, rather than positive-only, transport measures upwelling associated with the CEC: The net, annual-mean upwelling can be positive in a region only if there is a net divergence of upper-layer water; this divergence must be dynamically forced by the wind, and it is the origin of the CEC surface return flow. For the layer models, the difference between the positive-only and net transports measures the amount of the subduction in the region, but this interpretation is not possible for the JAMSTEC solution since $w$ includes isopycnal motions.

The values of net transports in the entire northern hemisphere are very similar for all three models, supporting the idea that the overall CEC strength is determined by the wind (Section 4). Values in the individual regions vary, however, indicating that regional upwelling is sensitive to model-dependent parameterizations. For all the solutions, there is significant upwelling in all three regions, with Somalia contributing somewhat more than the other two. The MKM and JAMSTEC solutions also roughly agree on the strength of upwelling in the $5^{\circ}-10^{\circ} \mathrm{S}$ band and off 
Sumatra. In contrast, the TOMS solution has less upwelling in the band and more off Somalia than the other two, likely because it is not fully adjusted to equilibrium (see below).

\subsubsection{Section and subduction transports}

Table 2 lists annual-mean horizontal transports for sections along the equator, $17^{\circ} \mathrm{S}$, the Indonesian passages (IT), and either $29^{\circ} \mathrm{S}$ for the MKM model or $30^{\circ} \mathrm{S}$ (SBND). At the equator, sections extend across the western-boundary-current region (EqWB) and the rest of the basin (EqIN), with the EqWB section being wide enough to include both the coastal current and related recirculations just off shore. At $17^{\circ} \mathrm{S}$, sections extend across the Mozambique channel (MOZ) and the rest of the basin (STB). The final two columns provide estimates of the subsurface flow across the southern boundary (SBND) and the subduction south of $17^{\circ} \mathrm{S}$ (SUB) associated with the CEC.

Both surface (in parentheses) and subsurface horizontal transports are listed. For the layer models, they are the layer-1 and layer-2 transports, respectively. For the JAMSTEC model, they are transports in the depth ranges $z<-80 \mathrm{~m}$ and $-500 \mathrm{~m}<z<-80 \mathrm{~m}$, the two depths being located near the center and bottom of the overturning circulation in the southern hemisphere (Fig. 2). Column SUB provides area integrations of net $w_{1}$ or $w$ at $80 \mathrm{~m}$ south of $17^{\circ} \mathrm{S}$ and east of the bifurcation trajectory defined at the end of Section 3.2.1. (For the layer models, the bifurcation trajectory is determined by the layer-2 flow field.) Column SBND lists subsurface transports east of the bifurcation latitude for the layer models or simply $\mathrm{STB}+|\mathrm{SUB}|$ for the JAMSTEC model because of complications due to vertical shear.

Table 2 provides measures for the strength of various CEC branches for each solution. (Transports do not exactly balance in closed boxes, due to remaining initial transients, to instabilities, or, for the TOMS and JAMSTEC solutions, to flows across the bottom of the boxes.) Consider the subsurface and surface branches of the MKM solution. The layer- 2 transport across $29^{\circ} \mathrm{S}$ that participates in the CEC is $3.1 \mathrm{~Sv}$. As this water flows northwards, it gains $11.7 \mathrm{~Sv}$ from subduction, and $15.3 \mathrm{~Sv}$ cross $17^{\circ} \mathrm{S}$. Of this amount, $5.2 \mathrm{~Sv}$ reverse direction to exit the basin through the Mozambique channel, $5.1 \mathrm{~Sv}$ is lost through upwelling into layer 1 from $17^{\circ} \mathrm{S}$ to the equator (less than "Band" in Table 1, which is integrated over a smaller area), and $5.8 \mathrm{~Sv}$ (EqWB + EqIN) flows into the northern hemisphere to participate in the CEC. [Transport EqIN is large because of the near-equatorial recirculation that allows water parcels to cross in the interior ocean (left panels of Fig. 3).] This northward flow is balanced by a net southward, cross-equatorial return flow in layer 1 of $-5.8 \mathrm{~Sv}$, with $-11.2 \mathrm{~Sv}$ in the interior ocean partially compensated by $5.4 \mathrm{~Sv}$ in the northwardflowing western boundary current. Note that the total (i.e., layer-1 plus layer-2), cross-equatorial transport in the interior ocean is $-8.7 \mathrm{~Sv}$, close to the cross-equatorial Sverdrup transport for the Hellerman and Rosenstein (1983) winds $(-8.1 \mathrm{~Sv})$, as it should be. Between the equator and $17^{\circ} \mathrm{S}$, the southward transport increases by $5.1 \mathrm{~Sv}$ due to

Table 2

Annual-mean transports across the equator, $17^{\circ} \mathrm{S}, 30^{\circ} \mathrm{S}$, and the eastern boundary for the MKM, TOMS, and JAMSTEC solutions

\begin{tabular}{|c|c|c|c|c|c|c|c|}
\hline \multirow[t]{2}{*}{ Model } & \multicolumn{7}{|l|}{ Section } \\
\hline & EqWB & EqIN & $\mathrm{MOZ}$ & STB & IT & SBND & SUB \\
\hline MKM & $3.3(5.4)$ & $2.5(-11.2)$ & $-5.2(-2.2)$ & $15.3(-9.6)$ & $0(0)$ & 3.1 & -11.7 \\
\hline TOMS & $6.2(3.4)$ & $1.2(-8.7)$ & $1.6(0.1)$ & $9.5(-12.8)$ & $2.7(2.4)$ & 6.5 & -2.0 \\
\hline JAMSTEC & $6.6(1.9)$ & $-0.5(-7.1)$ & $-7.7(-3.8)$ & $14.4(-14.4)$ & $5.1(5.7)$ & 9.7 & -4.7 \\
\hline
\end{tabular}

The transports (Sv) are obtained by integrating horizontal velocities across the equator (EqWB and EqIN), $17^{\circ} \mathrm{S}(\mathrm{MOZ}$ and $\mathrm{STB})$, the Indonesian passages (IT), and the southern boundary east of the bifurcation trajectory (SBND). Values without (with) parentheses are subsurface (surface) transports. Subduction transports obtained by integrating either $w_{1}$ or $w$ over the area south of $17^{\circ} \mathrm{S}$ and east of the bifurcation trajectory are also included. See the text for precise definitions of section locations and transport estimates. 
upwelling from layer 2, and $-11.8 \mathrm{~Sv}$ finally crosses $17^{\circ} \mathrm{S}$ to flow into the southern Indian Ocean.

Similar interpretations can be made for the transports in the TOMS and JAMSTEC solutions, with some noteworthy differences. Note, for example, that the net flow into the northern hemisphere $(\mathrm{EqWB}+\mathrm{EqIN}$ summed over both layers) is essentially zero for the MKM and JAMSTEC solutions but is $2.1 \mathrm{~Sv}$ for the TOMS solution, a consequence of its not being completely adjusted to equilibrium after only 6 years of integration. As for the MKM solution, the TOMS solution also has significant cross-equatorial flow in the interior ocean $(\mathrm{EqIN}=1.2 \mathrm{~Sv})$. This positive transport exists because part of the EACC bends offshore to meander back-and-forth across the equator in a damped standing-wave pattern (right panels of Fig. 3); the transport associated with the first southward meander is absorbed into EqWB, leaving a net negative positive contribution for EqIN.

Perhaps the most notable difference is that the relative strengths of sources of subsurface CEC water (IT, SBND, and SUB) vary considerably among the solutions. For example, the largest source for the MKM solution is subduction, whereas flow across the southern boundary is largest for the other two models. The reasons for these model differences are not clear. The total transport of subsurface water that enters the northern hemisphere is determined by the equatorial wind field, in order to balance the southward, cross-equatorial, near-surface Sverdrup transport (Section 4.1). The locations where the models obtain the subsurface water, though, depend on model-dependent factors such as basin boundary conditions and the mixing parameterizations that determine upwelling and subduction.

\section{Cross-equatorial flow}

As described in Section 3, the CEC surface branch can cross the equator at all longitudes. In this section, we first use the analytic model to illustrate the importance of the zonal wind-stress curl in driving this flow. Then, we use the LCS model, forced both by idealized and realistic winds, to confirm this theoretical result. The dynamical ideas discussed here are briefly mentioned in Godfrey et al. (2001) and Schott and McCreary (2001). Schopf (1980) and Jayne and Marotzke (2001) noted that $\tau^{x} / f$ was well defined at the equator and appealed to mass continuity and "direct" pressure forcing to explain crossequatorial flow, rather than adjustment to windcurl forcing.

\subsection{Theory}

Consider the response of the analytic model (1) to a zonal wind that is antisymmetric about the equator,

$\tau^{x}=\tau_{0} X(x) \frac{y}{L} T(t)$,

where $L$ is some width scale ( $5^{\circ}$ say), $\tau_{0}$ is a windstress amplitude, and $X(x)$ is an arbitrary $x$ structure. This wind field resembles the structure of the observed winds during both the summer and winter monsoons (July and January) when the equatorial zonal winds are weak (Fig. 1).

Solving (1) for an equation in $h$ alone yields

$h_{t}-\frac{\beta}{f^{2}} g^{\prime} h h_{x}=-\left(\frac{\tau^{x}}{f}\right)_{y} \equiv 0$,

where $\beta=f_{y}$. For this special wind field, then, the Ekman pumping velocity, $w_{\mathrm{e}}=\operatorname{curl} \tau / f$, vanishes. Assuming an initial state of rest in which $h$ has the constant value $H$, (4) implies that $h$ does not change. The solution to (4) is therefore

$h=H, \quad u=0, \quad v=-\frac{\tau^{x}}{f h}=-\frac{1}{\beta h} \tau_{y}^{x}$.

According to (4) and (5), no pressure gradients are ever generated by this wind field. It follows that there are no geostrophic currents so that the flow field is composed entirely of Ekman drift. Moreover, as indicated in (5), the Ekman transport $-\tau^{x} / f$ is equal to the Sverdrup transport $-\tau_{y}^{x} / \beta$.

Two corollaries are that the concept of Ekman flow can be extended to the equator (since $\tau^{x}$ tends to 0 as $f$ does) and that the Sverdrup flow spins up rapidly (in one inertial period) since no wave radiation is required to establish geostrophic 
currents. Thus, this simple solution provides a theoretical foundation for the hypothesis that cross-equatorial flow in the Indian Ocean is due to Ekman drift: Because the zonal wind is predominantly antisymmetric about the equator, the southward Ekman flows on either side of the equator also extend to the equator. It is interesting that these properties hold best in the nearequatorial region where $\tau^{x}$ most closely has the assumed linear dependence on $y$. Farther from the equator, where the winds no longer grow linearly in $y$, the geostrophic component is no longer negligible. So, this solution reverses conventional wisdom, stating that Ekman theory works best near the equator.

The potential-vorticity equation for the analytic model provides an alternate way of understanding the cause of interior cross-equatorial flow. The equation is

$q_{t}+\mathbf{v} \cdot \nabla q=-\frac{1}{h}\left(\frac{\tau^{x}}{h}\right)_{y}$

where $q=f / h$. According to (6), water parcels attain the $-\Delta q$ they need to cross the equator through forcing by wind curl.

A meridional wind $\tau^{y}$ can also drive crossequatorial flow. It is not possible to find timedependent solutions to the analytic model that illustrate the ocean's spin-up in response to $\tau^{y}$ : Since $w_{\mathrm{e}} \neq 0$ for $\tau^{y}$ forcing, the adjustment requires the radiation of equatorially trapped waves, and $u_{t}$ cannot be neglected. The steady (Sverdrup) response to (1) forced by both zonal and meridional winds yields the across-basin transport:

$M(y)=\frac{1}{\beta}\left[\bar{\tau}^{y}\left(x_{\mathrm{w}}, y\right)-\bar{\tau}^{y}\left(x_{\mathrm{e}}, y\right)\right]-\frac{1}{\beta} \int_{x_{\mathrm{w}}}^{x_{\mathrm{e}}} \bar{\tau}_{y}^{x} \mathrm{~d} x$,

where the overbar indicates the annual average, and $x_{\mathrm{w}}$ and $x_{\mathrm{e}}$ are the western and eastern edges of the basin. For the Hellerman and Rosenstein (1983) winds, the total cross-equatorial transport is $M=-8.1 \mathrm{~Sv}$, and of this amount only $-1.1 \mathrm{~Sv}$ is forced by $\bar{\tau}^{y}$. Thus, the cross-equatorial Sverdrup flow in the Indian Ocean is mostly determined by $\bar{\tau}_{y}^{x}$.

\subsection{Solutions forced by idealized winds}

We confirmed the validity of, and extended, the analytic results in numerical solutions to the LCS model, each forced by idealized zonal or meridional wind fields of the form $\tau=\tau_{0} X(x) Y(y)$ where $X(x)$ and $Y(y)$ are sinusoidal functions $\left[\cos \pi\left(\phi-\phi_{0}\right) / L\right.$ for $\left|\phi-\phi_{0}\right|<L / 2$ and 0 otherwise] and with $\tau_{0}=1 \mathrm{dyn} / \mathrm{cm}^{2}$. These simple solutions then provide a foundation for interpreting the more complex solutions driven by realistic winds reported in Section 4.3. Fig. 10 shows the wind stresses used in the experiments and results. Case (c) is forced by a zonal wind that is antisymmetric about the equator, and so is analogous to the analytic solution. For contrast, Cases (a) and (b) show the responses to zonal and meridional winds that are symmetric about the equator.

Case (a) develops a shallow overturning roll confined near the equator with a surface flow in the same direction as the wind, downwelling north of the equator, and upwelling south of it (see Section 5). Case (b) again develops an equatorial confined meridional circulation. It is symmetric about the equator with no crossequatorial velocity, and there is downwelling on the equator. Thus, neither of these symmetric wind fields drives a cross-equatorial flow that extends very far off the equator. Solutions similar to Cases (a) and (b) were discussed previously by Philander and Delecluse (1983) and McCreary (1985). As demonstrated in Section 5 for Case (a), vertical mixing is an essential part of their dynamics.

Case (c) is forced by an antisymmetric wind stress with negative curl, and it confirms all the properties predicted by the analytical solution. There is a southward flow that extends from $10^{\circ} \mathrm{S}$ to $10^{\circ} \mathrm{N}$, and the cross-equatorial transport is close to the Ekman transports to either side (at $\pm 5^{\circ}$ say). In addition, $v$ spins up in only a few days near the equator since $w_{\mathrm{e}}$ is nearly zero there. A difference from the analytic solution is that $u \neq 0$ off the equator, a consequence of $w_{\mathrm{e}}$ not being identically zero there and of the existence of vertical mixing. 

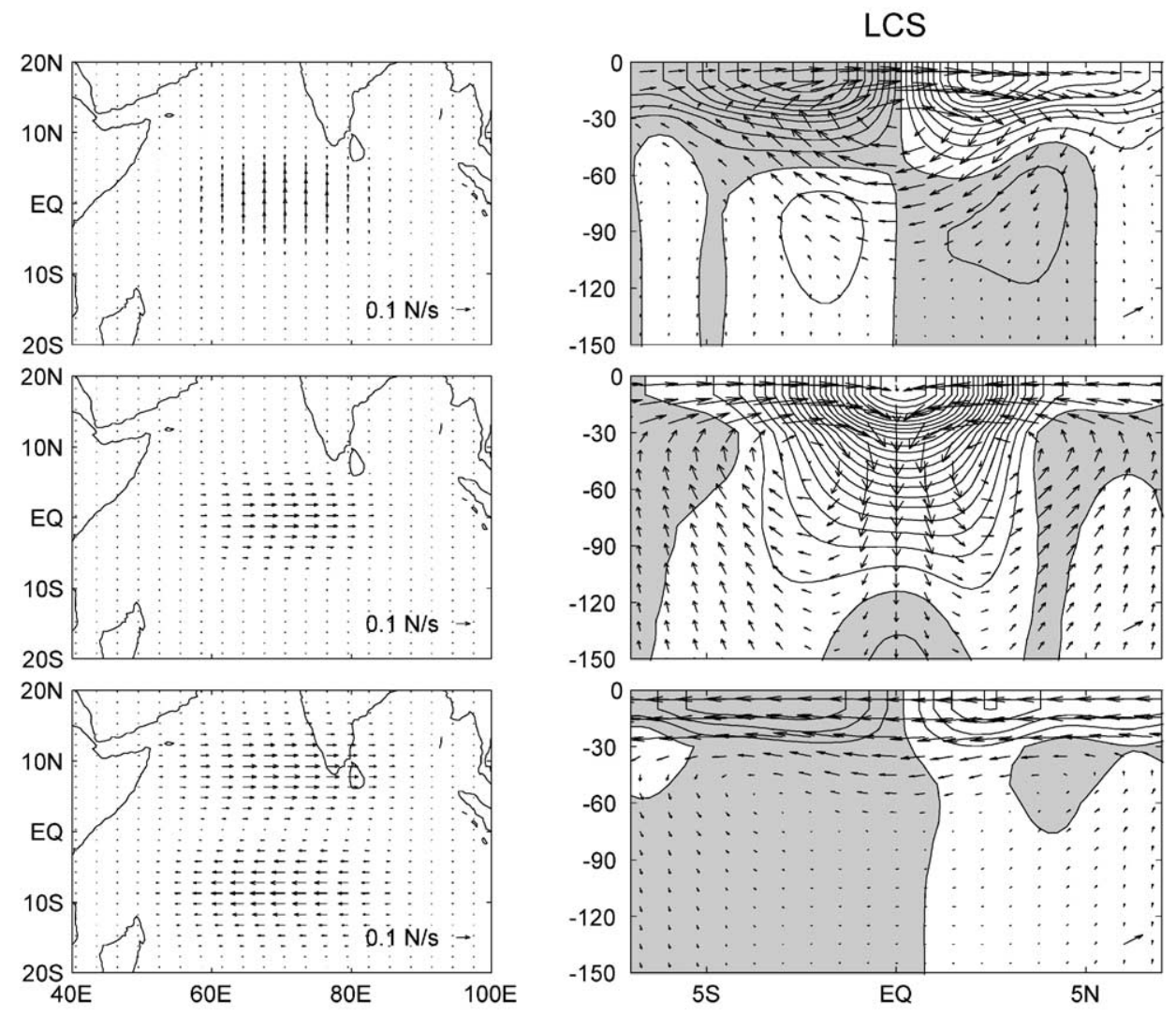

Fig. 10. Velocity fields of three solutions to the LCS model (right panels) and their forcing fields (left panels). The horizontal and vertical components of the slanted calibration arrow are $v=10 \mathrm{~cm} / \mathrm{s}$ and $w=0.001 \mathrm{~cm} / \mathrm{s}$, respectively. The contour interval for $u$ is $0.05 \mathrm{~m} / \mathrm{s}$, and negative (westward) contours are shaded.

\subsection{Solutions forced by realistic winds}

Fig. 11a illustrates the annual cycle of the nearequatorial flow field zonally averaged from $50^{\circ} \mathrm{E}$ to $90^{\circ} \mathrm{E}$ for the JAMSTEC (left panels) and LCS (right panels) models. The responses are not an aspect of the averaging window, but rather are typical of most longitudes across the basin. The similarity of the JAMSTEC and LCS solutions is striking, particularly for the meridional circulation ( $v$ and $w$ fields); this good agreement exists throughout the year, an indication that the basic dynamics of the flow are linear. Fig. 11b further divides the LCS solution into two parts, one driven only by $\tau^{x}$ (left panels) and another only by $\tau^{y}$ (right panels). Since the LCS model is linear, the sum of the two parts is equal to the corresponding right panel of Fig. 11a.

In July, the near-surface branch of the CEC is directed southward, but with a northward surface component at the equator due to the existence of the equatorial roll (lower-middle panels of Fig. 11a). Consistent with the analytic theory and idealized solutions, the southward cross-equatorial flow is driven by $\tau^{x}$ and the roll by $\tau^{y}$ (lowermiddle panels of Fig. 11b). In January, the forcing and circulation are oppositely directed and weaker than in July (top-left panel of Fig. 1; top panels of Fig. 11a), with a southward near-surface branch of the CEC underlying northward surface current near the equator. The reversed surface flows in the LCS solution are weaker than they are in the 
JAMSTEC solution; this difference cannot be eliminated by adjusting mixing parameters in the LCS model (see Section 5), and so is likely a nonlinear effect due to density advection. The shallowness of the cross-equatorial flow is striking, consistent with its dynamical relationship to Ekman flow; Fig. 13 of Lee and Marotzke (1997) nicely illustrates that the flow is shallow across the basin.

In April, the zonal wind stress near the equator becomes strong, generating a strong eastward jet, the springtime Wyrtki Jet (upper-middle panel of Fig. 11a; Wyrtki, 1973; Han et al., 1999). The meridional circulation develops downwelling on (a)
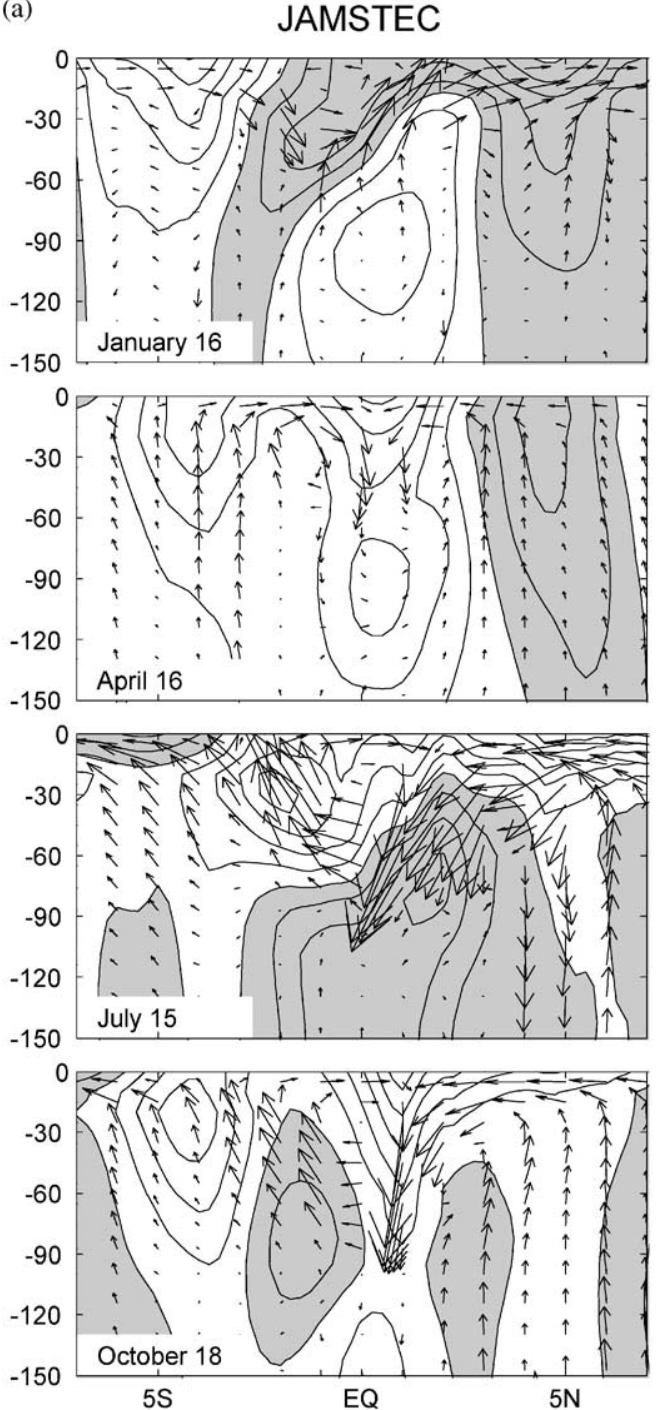

LCS
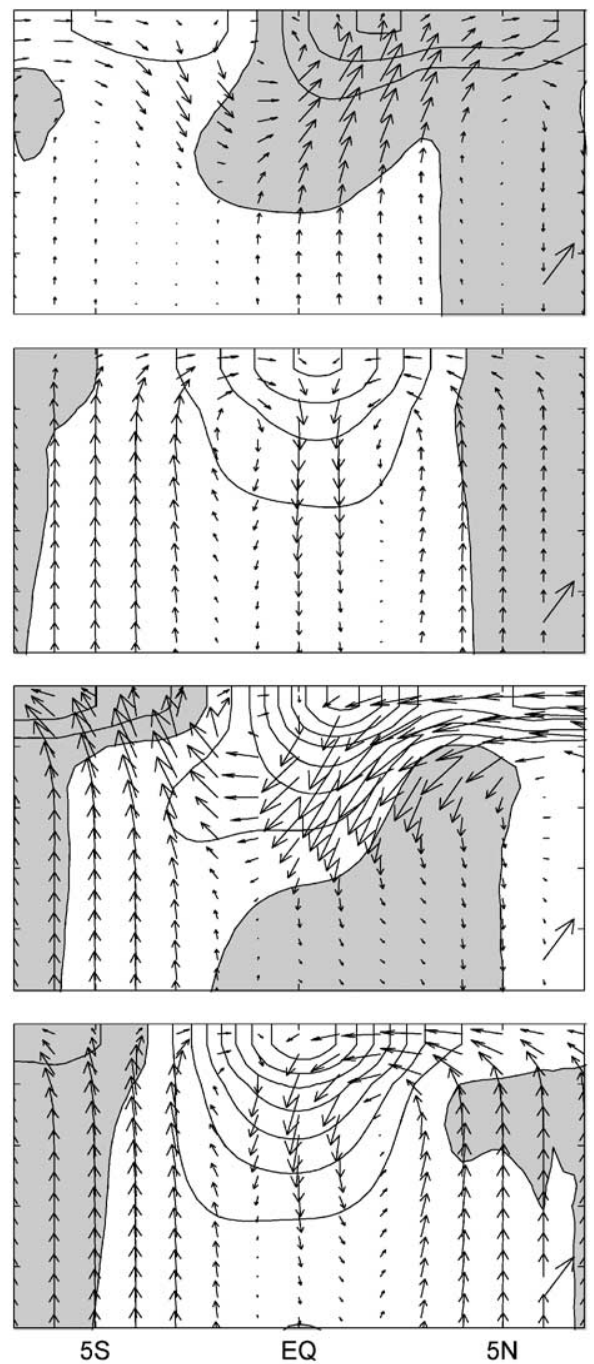

Fig. 11. (a) Velocity fields averaged between $40^{\circ} \mathrm{E}$ and $100^{\circ} \mathrm{E}$ for the JAMSTEC (left panels) and LCS (right panels) solutions forced by Hellerman and Rosenstein (1983) winds. The horizontal and vertical components of the slanted calibration arrow are $v=10 \mathrm{~cm} / \mathrm{s}$ and $w=0.001 \mathrm{~cm} / \mathrm{s}$, respectively. The contour interval for $u$ is $10 \mathrm{~cm} / \mathrm{s}$, and negative (westward) contours are shaded. (b) As in Fig. 11a, except showing solutions to the LCS model forced only by the zonal (left panels) and meridional (right panels) components of the Hellerman and Rosenstein (1983) wind stress. 
(b)

LCS, $\tau^{x}$
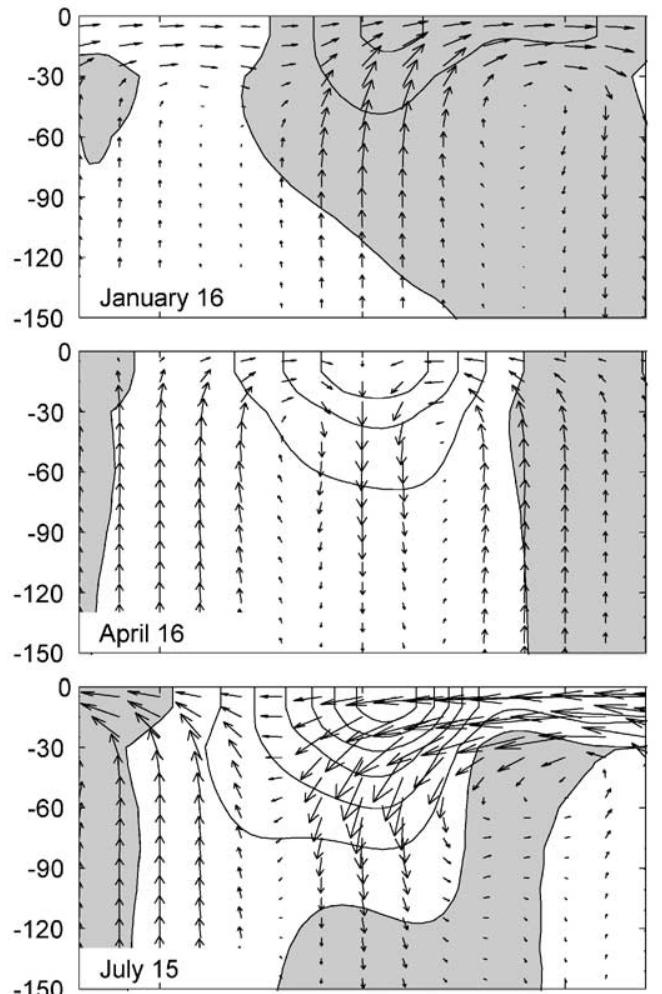

$-150$

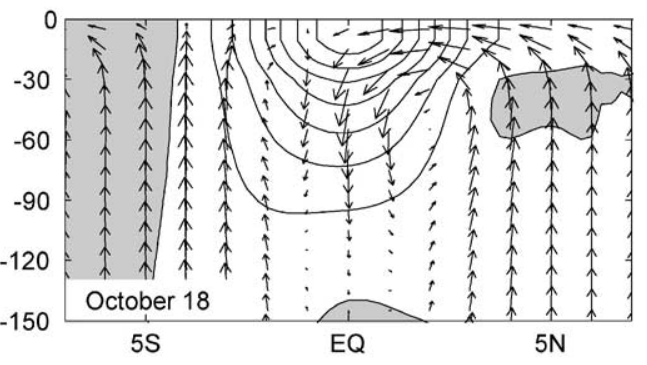

LCS, $\tau^{\mathrm{y}}$
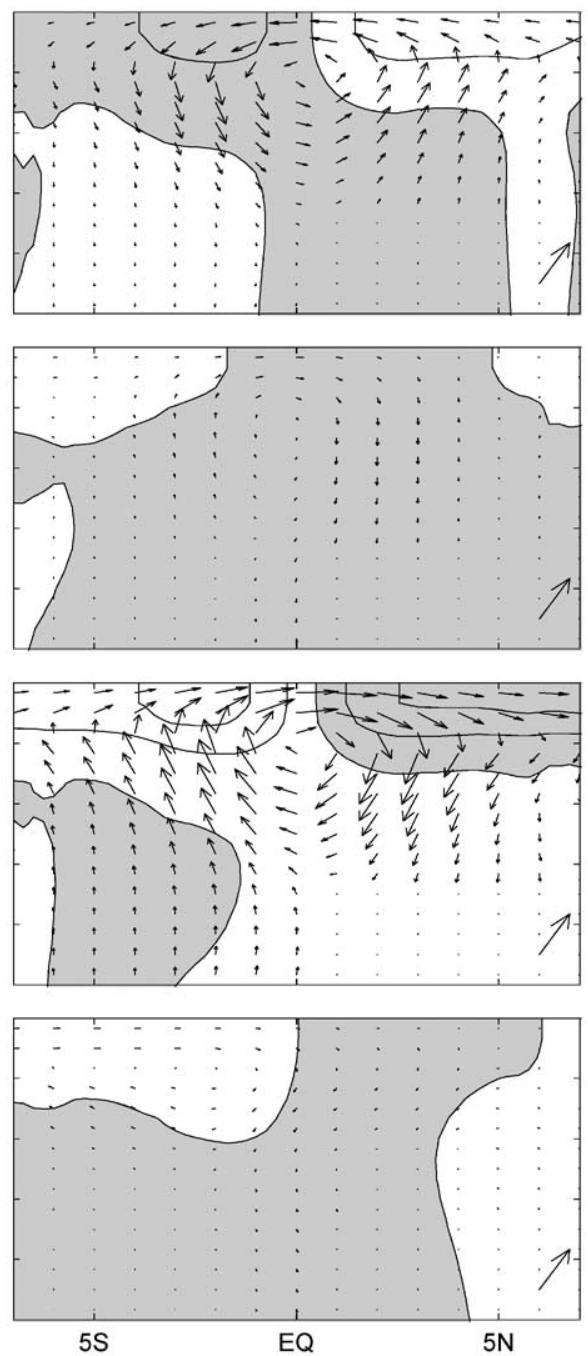

Fig. 11 (continued).

the equator, with recirculation cells on either side. These cells are clearly driven by $\tau^{x}$ (left uppermiddle panel of Fig. 11b), consistent with the idealized solution. Note that at this time there is also a weak roll driven by the weak $\tau^{y}$ field (right upper-middle panel of Fig. 11b). In October, the equatorial zonal wind again strengthens, and in response both models begin to develop downwelling near the equator (bottom panels of Figs. 11a and b).

\section{Equatorial roll}

In the previous section, we demonstrated that the shallow equatorial roll present in GCMs is driven by $\tau^{y}$ (top panels of Fig. 10, right panels of Fig. 11b). Prior studies have suggested that such rolls are a mixing-dominated response to $\tau^{y}$ (Philander and Delecluse, 1983; McCreary, 1985). Here, we demonstrate this property explicitly using the LCS model, illustrating the sensitivity of rolls 

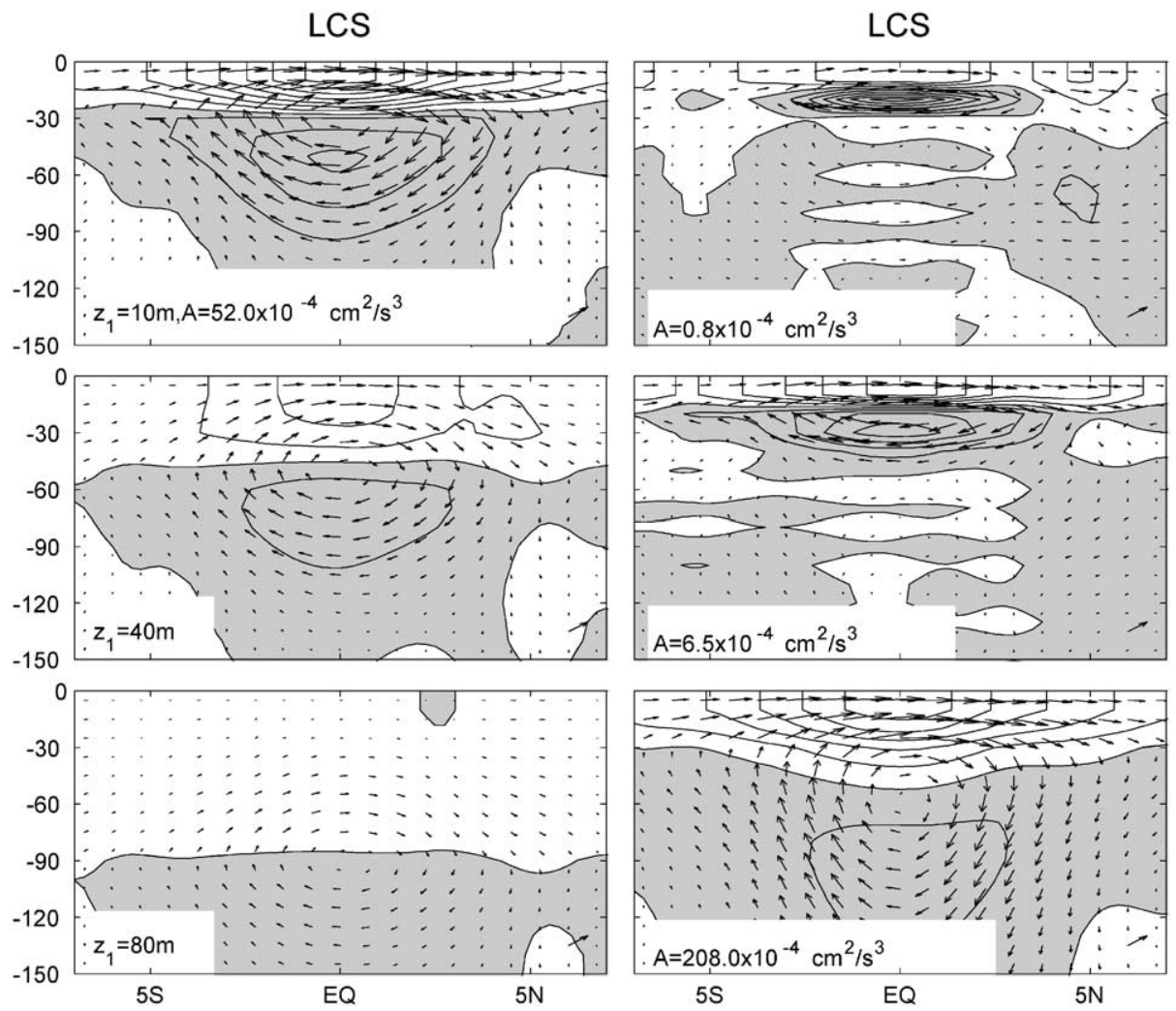

Fig. 12. Meridional sections of $v$ fields from LCS solutions for different values of mixing strength $A$ and mixed-layer thickness $\left|z_{1}\right|$, forced by the wind field shown in the top-left panel of Fig. 10 . In the left panels, $A=52 \times 10^{-4} \mathrm{~cm}^{2} / \mathrm{s}^{3}$ and $\left|z_{1}\right|=10,40$, and $80 \mathrm{~m}$ from top to bottom. In the right panels, $\left|z_{1}\right|=10 \mathrm{~m}$ and $A=0.8,6.5$, and $208 \times 10^{-4} \mathrm{~cm}^{2} / \mathrm{s}^{3}$ from top to bottom. The contour interval for $v$ is $5 \mathrm{~cm} / \mathrm{s}$, and negative contours are shaded.

to $A$, which measures the strength of the vertical mixing coefficient $v=A / N_{\mathrm{b}}^{2}$, and to mixed-layer thickness $\left|z_{1}\right|$. Fig. 12 shows solutions forced by the $\tau^{y}$ field in the top-left panel of Fig. 10 for various values of $A$ and $\left|z_{1}\right|$, plotting sections of $v$ and $w$ across the equator at $70^{\circ} \mathrm{E}$.

The basic dynamics of the roll in the LCS model can be understood by considering the different nature of the responses of low- and high-order modes. Vertical mixing appears as a damping term with coefficient $A / c_{n}^{2}$ in the equations for the $n$th mode, where $c_{n}$ is the mode's Kelvin-wave speed. Since $c_{n}$ tends to be inversely proportional to $n$, damping strength increases with $n$ roughly like $n^{2}$. For realistic choices of $A$, damping is negligible for the lowest-order modes, but it dominates for the high-order ones. As a consequence, the lowest- order modes adjust to a state of Sverdrup balance, which for the $\tau^{y}$ field of interest here consists of a weak, clockwise circulation about the wind patch, the responses of the high-order modes weaken with $n$, and the intermediate modes contribute most to solutions (McCreary, 1985). Just which intermediate mode makes the greatest contribution depends on the values of $A$ and $\left|z_{1}\right|$. The equatorial Rossby radius $\left(c_{n} / \beta\right)^{1 / 2}$ and the depth of the second zero crossing $z_{n}^{*}$ of this dominant mode provide measures for the width and depth scales of the roll. (Rolls also develop in a homogeneouslayer model. See McCreary, 1985, for a discussion of this simpler and instructive case.)

The top-left panel shows the response when $A$ and $\left|z_{1}\right|$ have the values specified in Section 2, namely, $A=52 \times 10^{-4} \mathrm{~cm}^{2} / \mathrm{s}^{3}$ and $\left|z_{1}\right|=10 \mathrm{~m}$. The 
right panels show the solutions when only $A$ is changed to $0.8 \times 10^{-4}, 6.5 \times 10^{-4}$, and $208 \times 10^{-4} \mathrm{~cm}^{2} / \mathrm{s}^{3}$. As $A$ increases, the higher-order modes are more strongly damped, the dominant mode shifts toward a lower $n$ value, and the roll broadens and deepens. As $A$ decreases, surface $v$ strengthens to a maximum value of $37 \mathrm{~cm} / \mathrm{s}$ when $A=52 \times 10^{-4} \mathrm{~cm}^{2} / \mathrm{s}^{3}$; thereafter, the roll weakens, and it vanishes completely when $A=0$.

The weakening for small $A$ is a consequence of the introduction of $\tau^{y}$ as a body force (i.e., of the model having a surface mixed layer). Indeed, when $\tau^{y}$ is introduced as a surface stress condition (i.e., when $\left.z_{1}=z_{2}=0\right), v$ continues to strengthen and the roll to thin as $A \rightarrow 0$. The effect of the body force can be most easily understood when $N_{\mathrm{b}}^{2}$ is a constant. Let $v^{*}$ designate the meridional velocity field of the surface-driven solution. Further, define $\tilde{v}^{*}$ to be $v^{*}$ extended into the regions $z>0$ and $z<-D$ by assuming symmetry about $z=0$ and $-D$. Then, the $v$ field forced by the body force $Z(z)$ is (Moore, 1978, unpublished manuscript)

$v(x, y, z, t)=\frac{1}{2} \int_{z-\left|z_{2}\right|}^{z+\left|z_{2}\right|} \tilde{Z}\left(z-z^{\prime}\right) \tilde{v}\left(x, y, z^{\prime}, t\right) \mathrm{d} z^{\prime}$.

According to Eq. (8), the effect of the body force is simply to convolve (smooth) the surface-driven solution with $\tilde{Z}$. Thus, when $z_{n}^{*}$ becomes less than $z_{1}$, the roll is increasingly averaged out. A similar smoothing occurs for variable $N_{\mathrm{b}}^{2}$, but it cannot be written in a closed form.

The middle-left and bottom-left panels of Fig. 12 show the responses when $\left|z_{1}\right|$ is 40 and $80 \mathrm{~m}$, respectively. As $\left|z_{1}\right|$ increases, the high-order modes project more weakly onto the body-force structure $Z(z)$ (as their $\left|z_{n}^{*}\right|$ becomes less than $\left|z_{2}\right|$ ), and so their relative contribution to the solution is decreased. As a result, the vertical structure of the roll broadens, and its surface branch is weaker.

The JAMSTEC model also introduces the wind stress as a step-function body force, one that extends down to the first grid level beneath the surface $(-10 \mathrm{~m})$. Not surprisingly, then, the JAMSTEC solution compares best to the LCS solution with $\left|z_{1}\right|=10 \mathrm{~m}$. The best-fit value for $A=52 \times 10^{-4} \mathrm{~cm}^{2} / \mathrm{s}$ is the one that yields the maximum surface $|v|$. For these choices, the strength, width, and thickness of the rolls in the JAMSTEC and LCS solutions are comparable, with the JAMSTEC roll being somewhat stronger due to density advection.

Despite its prominence, the equatorial roll does not have a major impact on basic CEC properties. In particular, it does not significantly impact the meridional heat transport, a consequence of its upwelling and downwelling branches having nearly the same temperatures (Wacongne and Pacanowski, 1996). To substantiate this result, we determined the heat budget in a box extending across the basin, from $3^{\circ} \mathrm{S}$ to $3^{\circ} \mathrm{N}$, and from the surface to $-50 \mathrm{~m}$. The heat fluxes into the box across its northern side, southern side, top and bottom are $-0.70,-0.79,0.08$, and $0.01 \mathrm{~W}$, respectively, confirming the relative weakness of the bottom flux.

On the other hand, the equatorial roll does affect the Lagrangian movement of surface drifters. Fig. 13 plots instantaneous trajectories of near-surface $(10 \mathrm{~m})$ drifters released on July 1 . They never cross the equator in the interior ocean, but rather only near the eastern boundary where the equatorial roll is weak. This property is not sensitive to release time. When the drifters are released on January 1, for example, almost all of them remain north of the equator until the following summer, since the wintertime wind curl drives a northward cross-equatorial Sverdrup flow (Section 4); in the following summer, they then follow pathways similar to those in Fig. 13. (The exception is for drifters that become entrained into the wintertime Somali Current, which is directed southward. After crossing the equator, however, they return to the northern hemisphere within the interior, northward, Sverdrup flow.) Observed drifters show a similar eastward movement with no interior crossings (Schott and McCreary, 2001), providing indirect support for the existence of the roll.

\section{Summary and discussion}

In this study, we utilize five different ocean models to study the CEC. Specifically, we determine the structure and strength of its various branches, and investigate the dynamics of its 


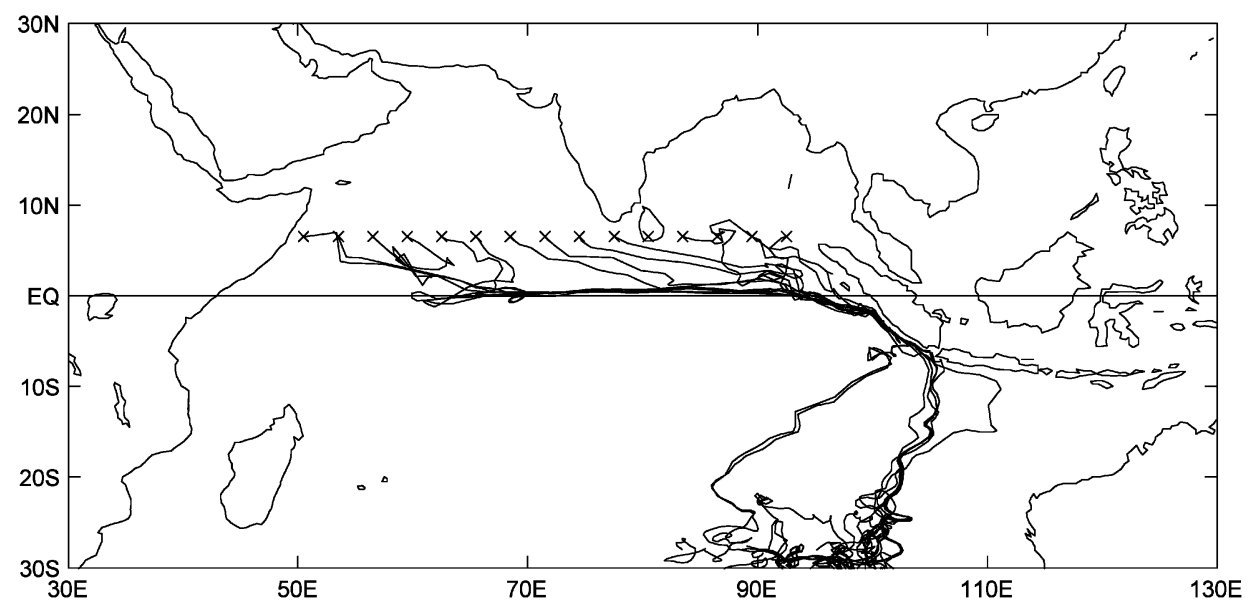

Fig. 13. Drifter trajectories at a depth of $10 \mathrm{~m}$ tracked forwards in time using the instantaneous velocity field of the JAMSTEC solution with $w=0$.

surface cross-equatorial flow and of equatorial rolls.

To illustrate CEC pathways, we track model drifters from the northern-hemisphere upwelling regions (Somalia, Oman, and India), forwards in time to follow the surface pathways and backwards in time to follow the subsurface flows. They indicate that sources of water for the subsurface CEC branch are subduction in the southeastern Indian Ocean, the Indonesian Throughflow, and flow into the basin across the southern boundary. These waters circulate around the Subtropical Gyre to the coast of Africa, and almost always cross the equator via the western boundary current, where boundary mixing can supply the necessary $+\Delta q$. In annual-mean trajectories for the MKM and TOMS solutions, subsurface water flows sequentially, first to Somalia, then to Oman, and finally to India, with some water upwelling in each region. In contrast, the annual-mean trajectories for the JAMSTEC solution flow directly to Somalia, follow a circuitous path to Oman, and extend to India near the equator. After subsurface water upwells in these regions, surface water crosses the equator at all longitudes, and either subducts in the southern Indian Ocean or exits the basin in the Agulhas Current, in the Leeuwin Current, or south of Madagascar.

Measures of CEC strength are the net, annualmean upwelling transport in the northern hemi- sphere (NH in Table 1) and surface and subsurface cross-equatorial transports $(\mathrm{EqWB}+\mathrm{EqIN}$ in Table 2). They have similar values for all the solutions (5-6 Sv), indicating that CEC strength is determined by the wind and does not depend on model mixing parameterizations. The models also agree that Somalia is the strongest of the three upwelling regions, but disagree on their relative strengths. They also disagree on the relative strengths of the sources (SBND, STB, and IT in Table 2).

The overall strength and structure of the CEC agree among the models, as they are determined largely by the wind. They can differ significantly on pathway segments, particularly where the annual-mean velocity is weak. On these segments, properties are determined by model-dependent physics, which include vertical-mixing parameterizations (e.g., those that determine upwelling and subduction) and basin boundary conditions (e.g., the presence or absence of the Indonesian Throughflow).

The surface cross-equatorial transport of the CEC is driven by wind curl associated with the zonal wind field. In the annual mean, $\tau^{x}$ is westerly north of the equator, easterly south of it, almost zero on the equator, and hence is roughly proportional to $y$. For such a wind field, $w_{\mathrm{e}}$ is identically zero, and hence it generates no pressure gradients or geostrophic currents. It follows that 
for this wind the Sverdrup and Ekman transports are equal, the Ekman drift is defined even on the equator, and the ocean adjusts to equilibrium rapidly in an equatorial inertial period. These results justify Levitus' (1987) hypothesis that Ekman dynamics account for the southward, annual-mean flow across the interior of the Indian Ocean.

In solutions to GCMs, the CEC surface branch typically crosses the equator below the surface, beneath an oppositely directed surface current that is part of a shallow, cross-equatorial "roll". The roll can also be simulated in LCS solutions, indicating that its basic dynamics are linear. Idealized solutions to the LCS model demonstrate that the roll is a direct (local) response to $\tau^{y}$, consistent with the conclusions of Wacongne and Pacanowski (1996). They also show how the strength, width, and depth of the roll depend on mixing strength $A$ and mixed-layer thickness $\left|z_{1}\right|$. Despite its prominence, the roll is not a thermodynamically important part of the CEC, having little effect on its heat transport because it is so shallow and equatorially confined.

As discussed above, the interior cross-equatorial flow is confined to the surface layer (specifically, to the same depth as the equatorial roll). This result has useful practical implications. In particular, the cross-equatorial flow in the interior ocean should be zero below the depth of the equatorial roll; so, the equatorial mooring array in the EACC reported by Schott et al. (1990) should have measured the total cross-equatorial flow, at all depths below the equatorial roll. Schott et al. (1990) already anticipated this result in their remark that the net subsurface EACC transport should equal the annual-mean Ekman flow across the equator (although they used values of $\tau^{x} / f$ on either side of the equator, since they assumed that Ekman transport was not well-defined there). For Hellerman and Rosenstein (1983) winds, the annual-mean, cross-equatorial Sverdrup transport is $8.1 \mathrm{~Sv}$, close to the subsurface EACC transport (10 Sv) estimated by Schott et al. (1990).

In conclusion, a defining property of the CEC is the existence of cross-equatorial flows. We have shown that they are determined by the annualmean, negative wind curl near the equator, which acts to drain near-surface water from the northern Indian Ocean and provides the necessary negative potential vorticity to allow surface water parcels to cross the equator in the interior ocean. The offequatorial structure of the CEC, however, is determined by other forcings: Its upwelling branches are driven by alongshore winds along Somalia, Oman, and India, and its downwelling branches are determined by Ekman pumping in the southern Indian Ocean and by factors external to the basin. There are also other shallow overturning cells in the Indian Ocean (the STC and eastern STC mentioned in Section 1.2) that share common branches with the CEC. Further modeling, and especially observational, studies are needed to investigate the influences of these other forcings and cells, as well as model-dependent physics, on CEC structure and its climatic variability.

\section{Acknowledgements}

We thank Fritz Schott for many stimulating discussions, and Weiqing Han for providing us the source code of the linear, continually stratified model. This research was supported by the Frontier Research System for Global Change through its sponsorship of the International Pacific Research Program (IPRC). The paper is SOEST Contribution No. 6057 and IPRC Contribution No. 180.

\section{References}

Fischer, J., Schott, F.A., Stramma, L., 1996. Currents and transports of the Great Whirl-Socotra Gyre system during the summer monsoon August 1993. Journal of Geophysical Research 101, 3573-3587.

Garternicht, U., Schott, F., 1997. Heat fluxes of the Indian Ocean from a global eddy-resolving model. Journal of Geophysical Research 102, 21147-21159.

Godfrey, J.S., Johnson, G.C., McPhaden, M.J., Reverdin, G., Wiffjels, S.E., 2001. The tropical ocean circulation. In: Seidler, G., Church, J., Gould, J. (Eds.), Ocean Circulation and Climate. Academic Press, San Diego, CA, pp. 215-246.

Haines, M.A., Fine, R.A., Luther, M.E., Ji, Z., 1999. Particle trajectories in an Indian Ocean Model and sensitivity to 
seasonal forcing. Journal of Physical Oceanography 29, 584-598.

Han, W., McCreary, J.P., Anderson, D.L.T., Mariano, A.J., 1999. Dynamics of the eastward surface jets in the equatorial Indian Ocean. Journal of Physical Oceanography 29, 2191-2209.

Hellerman, S., Rosenstein, M., 1983. Normal monthly wind stress over the world ocean with error estimates. Journal of Physical Oceanography 13, 1093-1104.

Huang, B., Liu, Z., 1999. Pacific subtropical-tropical thermocline water exchange in the national centers for environmental prediction ocean model. Journal of Geophysical Research 104, 11065-11076.

Ishida, A., Kashino, Y., Mitsudera, H., Yoshioka, N., Kadokura, T., 1998. Preliminary results of a global highresolution GCM experiment. Journal of the Faculty of Science, Hokkaido University, Series VII 1, 441-460.

Jayne, S.R., Marotzke, J., 2001. The dynamics of ocean heat transport variability. Reviews of Geophysics 39, 385-411.

Jensen, T.G., 1998. Open boundary conditions in stratified ocean models. Journal of Marine Systems 16, 297-322.

Kraus, E.B., Turner, J.S., 1967. A one-dimensional model of the seasonal thermocline II: the general theory and its consequences. Tellus 19, 98-106.

Lee, T., Marotzke, J., 1997. Inferring meridional mass and heat transports of the Indian Ocean by fitting a general circulation model to climatological data. Journal of Geophysical Research 102, 10585-10602.

Lee, T., Marotzke, J., 1998. Seasonal cycles of meridional overturning and heat transport of the Indian Ocean. Journal of Physical Oceanography 28, 923-943.

Levitus, S., 1982. Climatological Atlas of the World Ocean. NOAA Prof. Paper No. 13, US Government Printing Office, Washington, DC, 173pp.

Levitus, S., 1987. Meridional Ekman heat fluxes for the world ocean and individual ocean basins. Journal of Physical Oceanography 14, 727-746.

Levitus, S., Boyer, T.P., 1994. World Ocean Atlas 1994, Vol. 4, Temperature. NOAA Atlas NESDIS, Vol. 4. US Government Printing Office, Washington, DC, 117pp.

Levitus, S., Burgett, R. Boyer, T.P., 1994. World Ocean Atlas 1994, Vol. 5, Salinity. NOAA Atlas NESDIS, Vol. 3. US Government Printing Office, Washington, DC, 99pp.

Lu, P., McCreary, J.P., Klinger, B.A., 1998. Meridional circulation cells and the source waters of the pacific equatorial undercurrent. Journal of Physical Oceanography 28, 62-84.

Malonotte-Rizzoli, P., Hedstrom, K., Arango, H., Haidvogel, D., 2000. Water mass pathways between the subtropical and tropical ocean in a climatological simulation of the North Atlantic ocean circulation. Dynamics of Atmospheres and Oceans 32, 331-371.
McCreary, J.P., 1985. Modeling equatorial ocean circulation. Annual Review of Fluid Mechanics 17, 359-409.

McCreary, J.P., Kundu, P.K., Molinari, R.L., 1993. A numerical investigation of dynamics, thermodynamics, and mixed-layer processes in the Indian Ocean. Progress in Oceanography 31, 181-244.

McCreary, J.P., Han, W., Shankar, D., Shetye, S.R., 1996. Dynamics of the East India Coastal Current: Part 2, numerical solutions. Journal of Geophysical Research 101, 13993-14010.

Murtugudde, R., Signorini, S., Christian, J., Busalacchi, A., McLain, C., Picaut, J., 1999. Ocean color variability of the tropical Indo-Pacific basin observed by SeaWIFS during 1997-98. Journal of Geophysical Research 104, 18351-18366.

Pacanowski, R., 1995. MOM2 Documentation User's Guide and Reference Manual, Version 1.0. GFDL Ocean Group Technical Report No. 3. Geophysical Fluid Dynamics Laboratory, Princeton, USA.

Pacanowski, R., Philander, S.G.H., 1981. Parameterization of vertical mixing in numerical models of the tropical ocean. Journal of Physical Oceanography 11, 1442-1451.

Philander, S.G.H., Delecluse, P., 1983. Coastal currents in low latitudes. Deep-Sea Research 30, 887-902.

Rothstein, L.M., Zhang, R.-H., Busalacchi, A.J., Chen, D., 1998. A numerical simulation of the mean water pathways in the subtropical and tropical Pacific Ocean. Journal of Physical Oceanography 28, 322-343.

Schopf, P.S., 1980. The role of Ekman flow and planetary waves in the oceanic cross-equatiorial heat transport. Journal of Physical Oceanography 10, 330-341.

Schott, F.A., McCreary, J.P., 2001. The monsoon circulation of the Indian Ocean. Progress in Oceanography 51, 1-123.

Schott, F., Swallow, J.C., Fieux, M., 1990. The Somali current at the equator: annual cycle of currents and transports in the upper $1000 \mathrm{~m}$ and connection to neighboring latitudes. Deep-Sea Research 37, 1825-1848.

Schott, F., Dengler, M., Schoenefeldt, R., 2002. Observations of shallow cross-equatorial cells in the Indian Ocean. Progress in Oceanography 53, 57-103.

Spencer, D., Broecker, W.S., Craig, H., Weiss, R.F., 1982. GEOSECS Indian Ocean Expedition, Vol. 6, Sections and Profiles. National Science Foundation, 140pp, Washington DC.

Wacongne, S., Pacanowski, R.C., 1996. Seasonal heat transport in a primitive equation model of the tropical Indian Ocean. Journal of Physical Oceanography 26, 2666-2699.

Wyrtki, K., 1973. An equatorial jet in the Indian Ocean. Science 191, 262-264.

Wyrtki, K., 1988. Oceanographic Atlas of the International Indian Ocean Expedition. Amerind Publishing Co. Pvt. Ltd., New Delhi, India. 